\title{
An Alternative Bias Correction Scheme for CrIS Data Assimilation in a Regional Model
}

\author{
XIN LI \\ Key Laboratory of Transportation Meteorology, CMA, and Jiangsu Research Institute of Meteorological Sciences, \\ and Nanjing Joint Center of Atmospheric Research, Nanjing, China \\ XiAOLEI ZOU \\ Cooperative Institute for Climate and Satellites, Earth System Science Interdisciplinary Center, \\ University of Maryland, College Park, College Park, Maryland \\ MingJiAn ZENG \\ Key Laboratory of Transportation Meteorology, CMA, and Jiangsu Research Institute of Meteorological Sciences, \\ and Nanjing Joint Center of Atmospheric Research, Nanjing, China
}

(Manuscript received 4 February 2018, in final form 20 December 2018)

\begin{abstract}
Bias correction (BC) is a crucial step for satellite radiance data assimilation (DA). In this study, the traditional airmass BC scheme in the National Centers for Environmental Prediction (NCEP) Gridpoint Statistical Interpolation (GSI) is investigated for Cross-track Infrared Sounder (CrIS) DA. The ability of the airmass predictors to model CrIS biases is diagnosed. Correlations between CrIS observation-minusbackground $(O-B)$ samples and the two lapse rate-related airmass predictors employed by GSI are found to be very weak, indicating that the bias correction contributed by the airmass BC scheme is small. A modified BC scheme, which directly calculates the moving average of $O-B$ departures from data of the previous 2 weeks with respect to scan position and latitudinal band, is proposed and tested. The impact of the modified BC scheme on CrIS radiance DA is compared with the variational airmass BC scheme. Results from 1-month analysis/forecast experiments show that the modified BC scheme removes nearly all scan-dependent and latitude-dependent biases, while residual biases are still found in some channels when the airmass BC scheme is applied. Smaller predicted root-mean-square errors of temperature and specific humidity and higher equivalent threat scores are obtained by the DA experiment using the modified BC scheme. If $O-B$ samples are replaced by observation-minus-analysis $(O-A)$ samples for bias estimates in the modified $\mathrm{BC}$ scheme, the forecast impacts are reduced but remain positive. A convective precipitation case that occurred on 21 August 2016 is investigated. Using the modified BC scheme, the atmospheric temperature structure and the geopotential height structures near trough/ridge areas are better resolved, resulting in better precipitation forecasts.
\end{abstract}

\section{Introduction}

The good performance of numerical weather forecasts highly depends on the accuracy of initial conditions. In modern numerical weather prediction (NWP), optimal analysis fields are estimated from previous model forecasts and multisource meteorological observations by data assimilation (DA). Compared with conventional observational data, satellite measurements can observe atmospheric structures with better spatial and temporal

Corresponding author: Dr. X. Zou, xzou1@umd.edu coverages. Sensitive to the temperature and humidity of the atmospheric and/or the Earth surface conditions, satellite infrared and microwave radiances are of great value in support of NWP. Among the operational uses of infrared radiances, hyperspectral infrared radiance sounders, such as the Atmospheric Infrared Sounder (AIRS; Aumann et al. 2003), the Infrared Atmospheric Sounding Interferometer (IASI; Klaes et al. 2007), and the Cross-track Infrared Sounder (CrIS; Han et al. 2013), have become increasingly important and demanding because atmospheric information at high vertical resolutions is provided by their large numbers of channels. 
This is especially so when the atmospheric structures present significant baroclinity (Prunet et al. 1998).

Like earlier hyperspectral sounders (i.e., AIRS and IASI), CrIS is now widely used in operational centers around the world and provides important support for NWP (Collard et al. 2012; Eresmaa et al. 2017). CrIS is a hyperspectral Fourier transform spectrometer that has flown on board the Suomi National Polar-Orbiting Partnership (S-NPP) satellite since 2011. It provides infrared radiances in the following three separate spectral bands: longwave infrared (LWIR; $650-1095 \mathrm{~cm}^{-1}$ ), midwave infrared (MWIR; $1210-1750 \mathrm{~cm}^{-1}$ ), and shortwave infrared (SWIR; $2155-2550 \mathrm{~cm}^{-1}$ ) bands. The channel spacing of the LWIP, MWIR, and SWIR bands is $0.625,1.25$, and $2.5 \mathrm{~cm}^{-1}$, respectively. Since 18 November 2017, CrIS has been on board the Joint Polar Satellite System-1 (JPSS-1) satellite, which is also known as National Oceanic and Atmospheric Administration-20 (NOAA-20). The new CrIS operates with a full spectral resolution (FSR) and a uniform channel spacing of $0.625 \mathrm{~cm}^{-1}$ over the three LWIP, MWIR, and SWIR bands.

Aimed at improving the assimilation of CrIS radiances in NWP applications, some efforts have been made focusing on channel selection (Gambacorta and Barnet 2013), bias characterization (Smith et al. 2015; $\mathrm{Li}$ and Zou 2017), cloud detection (Liang and Weng 2014; Lin et al. 2017), and interchannel error corrections (Eresmaa et al. 2017). Among these efforts, bias correction (BC) is regarded as a basic step to do before satellite radiance DA (Dee 2005). One reason is that since the background and observation errors are assumed to be unbiased Gaussian in DA, relative biases between satellite-observed and model-simulated radiances should be removed as a necessary condition for meeting this requirement. Another reason is that corrected brightness temperatures are also necessary for other processes within DA, such as cloud detection (McNally and Watts 2003), which depends on observation-minus-background $(O-B)$ departures (Auligné and McNally 2007).

Biases between satellite-observed and model-simulated radiances arise from instrument errors, limitations of the radiative transfer model (RTM), inaccurate preprocessing (i.e., cloud detection), and errors in the NWP model background. Tracing back to the very beginning of satellite DA, the BC term was treated as a global offset for each channel at NWP centers such as the European Centre for Medium-Range Weather Forecasts (Kelly and Flobert 1988). Eyre (1992) discussed the airmass-dependent nature of radiance biases and proposed a $\mathrm{BC}$ scheme for Television and Infrared Observation Satellite Operational Vertical Sounder (TOVS) radiances. Brightness temperature observations from Microwave Sounding Unit channels 2, 3, and 4 were used as bias predictors for all satellite measurements. Harris and Kelly (2001) proposed an updated $\mathrm{BC}$ scheme that replaced observation-based predictors by NWP model-based predictors. These earlier airmass BC schemes were designed to correct the scan-varying and geographically varying components of satellite data biases. The coefficients of the predictors were generated by an offline multiple linear regression using samples of $O-B$ departures prior to assimilation times. With the purpose of updating the airmass BC during the analysis, the variational BC was then developed (Derber and Wu 1998; Dee 2004; Auligné et al. 2007; Zhu et al. 2014a), which allowed the coefficients of airmass predictors to be adjusted together with the analysis control variables in the DA system. These variational schemes take account of the time-varying feature of satellite biases and also take advantage of constraining the corrections by other sources of observational data.

The BC scheme currently used for CrIS radiances in the National Centers for Environmental Prediction (NCEP) Gridpoint Statistical Interpolation (GSI) system originates from the airmass method discussed previously. The BC scheme for CrIS radiance DA shares the same set of airmass predictors as other earlier satellite instruments (e.g., the High-Resolution Infrared Radiation Sounder, AIRS). In essence, the airmass BC scheme is based on the idea that the scan-dependent and geographical-dependent components of biases can be modeled by a linear combination of the selected predictors. As a premise, it is necessary to diagnose if the model-based predictors in the GSI system could characterize the CrIS bias features of all the channels that are operationally assimilated. If the correlations between the $O-B$ samples and the GSI-selected predictors are weak, the linear regression of the $O-B$ to these predictors may be inefficient. On the other hand, as calibration and validation technologies have advanced (Goldberg et al. 2011; Chander et al. 2013), satellite data quality has greatly improved during the last 30 years. For CrIS, high data accuracy (Han et al. 2013) is supported by comprehensive efforts, including radiometric calibration (Tobin et al. 2013), spectral calibration and validation (Strow et al. 2013), and geometric assessment (Wang et al. 2013). As a result, satellite measurement biases are assumed to be much less significant than before. From this point of view, it is meaningful for this study to examine whether a simpler BC scheme based on a statistical approach that directly samples $O-B$ departures from previous time periods can serve as a substitute for the more complex airmass BC scheme.

The article is organized as follows. CrIS radiance data that are used in operational NWP are discussed in 
TABLE 1. Groups of actively assimilated CrIS LWIR channels.

\begin{tabular}{cccc}
\hline \hline Group No. & \multicolumn{1}{c}{ Description } & Channel No. & WF peak \\
\hline 1 & $\mathrm{CO}_{2}$ channels, stratospheric sounding & $37,49,51,53,59,61,63,64,65,67,69,71$, & Above 250 hPa \\
& & $73,75,79,80,81,83$ & \\
2 & $\mathrm{CO}_{2} / \mathrm{H}_{2} \mathrm{O}$ channels, upper-tropospheric sounding & $85,87,88,89,93,95,96,99,101,102,104,106$, & $250-650 \mathrm{hPa}$ \\
& & $107,130,132,147,148$ & \\
3 & $\mathrm{CO}_{2} / \mathrm{H}_{2} \mathrm{O}$ channels, lower-tropospheric sounding & $116,120,123,124,125,126,133,136,137,138$, & $\mathrm{Below} 650 \mathrm{hPa}$ \\
& & $142,143,144,145,150,151,153,154,155$, & \\
& & $157,158,159,160,161,162,163,164,165$, & Near surface \\
4 & \multirow{2}{*}{ Surface channels } & $166,168,170,171,173,175$ & \\
& & $198,211,224,279,311,342,392,404,427,464$, & \\
\hline
\end{tabular}

section 2. In section 3, the dependence of CrIS biases on the airmass predictors employed by the NCEP GSI system is diagnosed by investigating a clear-sky $O-B$ data sample. In section 4 , a simpler modified BC scheme that takes into account the dependences of bias on latitude and scan angle is proposed for CrIS assimilation. Section 5 examines the impact of the modified BC scheme on CrIS radiance DA in a regional NWP application and compares this with the impact of the traditional GSI airmass BC scheme. Section 6 discusses the probability of potentially correcting NWP model bias when the modified BC scheme is used in a regional model. Summary and conclusions are given in section 7 .

\section{CrIS data description}

In this study, CrIS radiance data from the $S$-NPP satellite are used for DA research. As briefly described in section $1, S-N P P / C r I S$ is a hyperspectral Fourier transform interferometer, which has 1305 channels covering three spectral bands (i.e., LWIR, MWIR, and SWIR) from 650 to 1095,1210 to 1750 , and 2155 to $2550 \mathrm{~cm}^{-1}$, respectively. As a cross-track sounder, CrIS measures Earth scene views at 30 cross-scan positions, also known as fields of regard (FORs), in one single scan. The satellite zenith angles of these FORs vary from $-48.3^{\circ}$ to $+48.3^{\circ}$, with an approximate interval of $3.3^{\circ}$. Each FOR consists of a $3 \times 3$ array of fields of view (FOVs), and the approximate radius for the nadir FOV is $14 \mathrm{~km}$.

Considering the computational feasibility and the interchannel correlation issue, NCEP used a subset of 399 channels out of the original 1305 channels, which were selected by Gambacorta and Barnet (2013) for NWP applications. This subset of channels consists of 184 LWIR, 128 MWIR, and 87 SWIR channels, which contain the majority of information presented by the wholespectrum 1305 channels. Among the 399 NWP channels, only 84 channels located in the LWIR carbon dioxide $\left(\mathrm{CO}_{2}\right)$ and surface-sensitive band are actively assimilated in the NCEP GSI system. Other channels located in the LWIR ozone $\left(\mathrm{O}_{3}\right)$, MWIR water $\left(\mathrm{H}_{2} \mathrm{O}\right)$, methane, carbon monoxide, and nitrous oxide bands, and SWIR channels serve as monitoring channels. Figure 1a shows simulated brightness temperatures and corresponding weighting function (WF) peaks for CrIS LWIR channels calculated from a typical clear-sky atmospheric profile. According to the sensitivity analysis by Gambacorta and Barnet (2013), CrIS LWIR channels cover the bands sensitive to $\mathrm{CO}_{2}, \mathrm{H}_{2} \mathrm{O}, \mathrm{O}_{3}$, and surface temperature. In NCEP operational use, the 84 actively assimilated channels (Table 1) consist of stratospheric $\mathrm{CO}_{2}$ channels (indicated by blue dots), upper- and lower-tropospheric $\mathrm{CO}_{2} / \mathrm{H}_{2} \mathrm{O}$ channels (indicated by green and orange dots), and surface channels (indicated by red dots). Figure $1 \mathrm{~b}$ displays the vertical distributions of normalized WFs for LWIR channels. The actively assimilated channels cover high observing resolutions in the vertical dimension, which provide meteorological information about the atmospheric layers extending from the surface to the stratosphere.

\section{Dependence of CrIS biases on airmass predictors}

\section{a. A brief description of the GSI airmass BC scheme}

In this section, we investigate the airmass predictors used by the NCEP GSI system and diagnose whether they are correlated to the biases of the CrIS channels. The five predictors $P_{n, i, j}(\mathbf{x})(n=1, \ldots, 5)$ for airmass correction in the GSI system are summarized as follows:

$$
\begin{aligned}
& P_{1, i, j}=0.01 \\
& P_{2, i, j}=\frac{1}{10} \times\left(\frac{1}{\cos \theta}-1\right)^{2}-0.015 \\
& P_{3, i, j}=\operatorname{clw} \times(\cos \theta)^{2} \\
& P_{4, i, j}=\left(\Gamma_{i, j}-\overline{\Gamma_{i}}\right)^{2} \\
& P_{5, i, j}=\Gamma_{i, j}-\overline{\Gamma_{i}},
\end{aligned}
$$


(a)

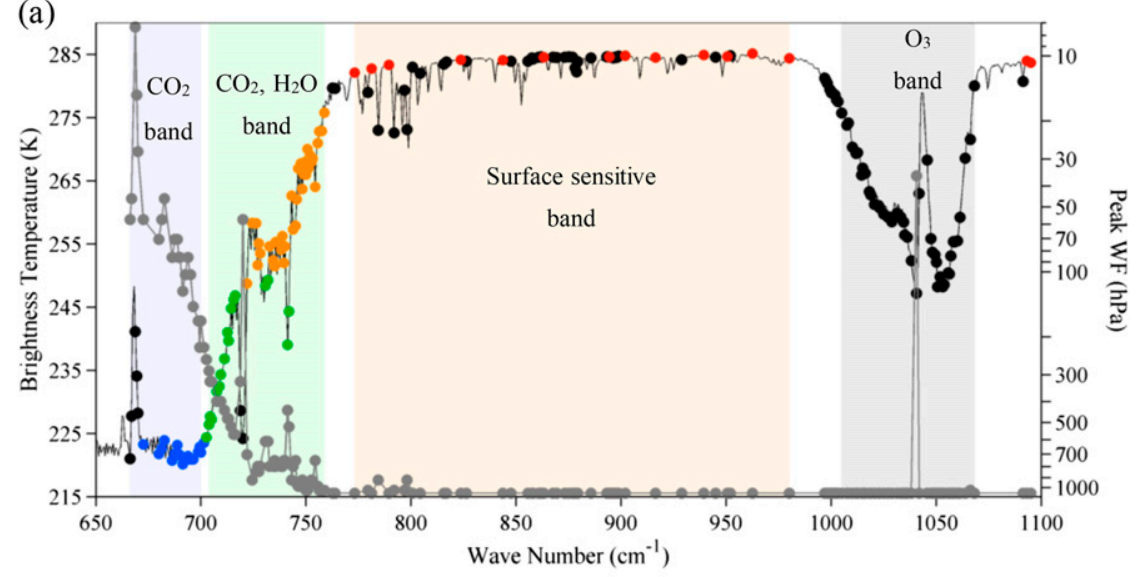

(b)

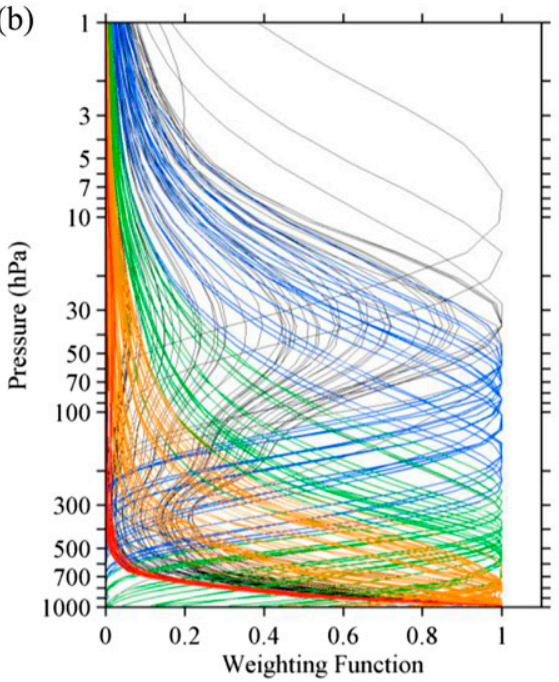

FIG. 1. (a) Brightness temperatures (black curve) and WF peaks (gray curve) for CrIS LWIR channels calculated by the CRTM using a typical tropical atmosphere profile. Blue, green, orange, and red dots indicate the stratospheric channels, upper-tropospheric channels, lower-tropospheric channels, and surface channels, respectively, which are actively assimilated in the GSI system. Black dots indicate the other LWIR channels that are used as monitoring channels. (b) Normalized WFs for LWIR. The blue, green, orange, and red curves indicate the stratospheric channels, uppertropospheric channels, lower-tropospheric channels, and surface channels, respectively.

where the subscripts $i$ and $j$ stand for the indices of channels and scan positions, respectively.

The first predictor is a globally constant offset term. The second predictor is a function of satellite zenith angle $\theta$, designed for correcting residual scan-dependent biases. For nonmicrowave sensors, the third predictor can be neglected because the cloud liquid water (CLW) is 0 . The fourth and fifth predictors are the "lapse rate" predictors, where the former is the square of the latter. Parameter $\Gamma_{i, j}$ is the vertical integration of the lapse rate $\left(T_{k-1}-T_{k+1}\right)$ multiplied by the difference in transmittances $\left(\tau_{k+1}-\tau_{k}\right)$ from adjacent vertical levels, where $k$ indicates the $k$ th vertical level, and $K$ is the total number of vertical levels. Parameter $\Gamma_{i, j}$ is calculated as

$$
\Gamma_{i, j}=-0.01 \times \sum_{k=1}^{K-1}\left(\tau_{k+1}-\tau_{k}\right) \times\left(T_{k-1}-T_{k+1}\right) ;
$$

$\overline{\Gamma_{i}}$ is the averaged $\Gamma_{i, j}$ over all FORs for the $i$ th channel. In essence, the fourth and fifth predictors can also be understood as the lapse rate convolved with the WF.

According to Eq. (1), only the fourth and fifth predictors actually reflect the airmass nature for infrared sensors. The temperature lapse rate has different patterns in different geographical regions and under different weather conditions, both of which are regarded to represent the latitudinal-varying features of the atmosphere. In addition, the vertical transmittance profiles of the fourth and fifth predictors are 
designed to reflect instrument and RTM errors. When the channel frequency is shifted, or the spectroscopy is inaccurately set in the RTM, the calculated transmittance profile will move up/down in the atmosphere when the atmosphere is not isothermal. For these reasons, the NCEP GSI system has employed these two predictors for airmass $\mathrm{BC}$.

The total airmass BC term is calculated as the sum of these five scan-dependent and state-dependent predictors $P_{n, i, j}(\mathbf{x})$ multiplied by their associated coefficients $\beta_{n, i}$, expressed as $\sum_{n=1}^{N} \beta_{n, i} \times P_{n, i, j}(\mathbf{x})$. The number $N$ is the total number of predictors. The coefficients $\beta_{n, i}$ are updated globally for each channel through the variational BC scheme (Dee 2004; Auligné et al. 2007; Zhu et al. 2014a).

Along with the airmass correction term, the GSI BC also consists of a scan-angle correction term $a_{i, j}$, updated offline outside the GSI system as a function of channel number and scan position. The total bias correction is represented as

$$
\mu=a_{i, j}+\sum_{n=1}^{N} \beta_{n, i} \times P_{n, i, j}(\mathbf{x}) .
$$

Finally, in the variational cost function, the BC toward observation departures is equivalent to applying a modified observation operator:

$$
\tilde{H}(\mathbf{x}, \beta)=H(\mathbf{x})+a_{i, j}+\sum_{n=1}^{N} \beta_{n, i} \times P_{n, i, j}(\mathbf{x}) .
$$

Note that Zhu et al. (2014a) proposed a one-step 'variational angle bias correction scheme, in which the scan-angle component of bias is updated inside the GSI through a fourth-order polynomial fit. Zhu et al. (2014b) also introduced an additional emissivity sensitivity predictor over land and sea for surfacesensitive channels. These new updates are used in the global operational model but not in regional applications.

\section{b. Statistical diagnoses}

To investigate the correlation between airmass predictors and the $O-B$ bias of each CrIS channel, 2-week-long offline $O-B$ departure statistics are used, which are sampled covering the period from 3 to 16 September 2016. The Community Radiative Transfer Model (CRTM; Weng 2007; Han et al. 2007) is employed as the forward RTM to simulate CrIS brightness temperatures. NCEP Global Forecast System (GFS) analyses with a horizontal resolution of $0.25^{\circ} \times 0.25^{\circ}$, valid at $0000,0600,1200$, and $1800 \mathrm{UTC}$, are used as input to the CRTM. To collocate model
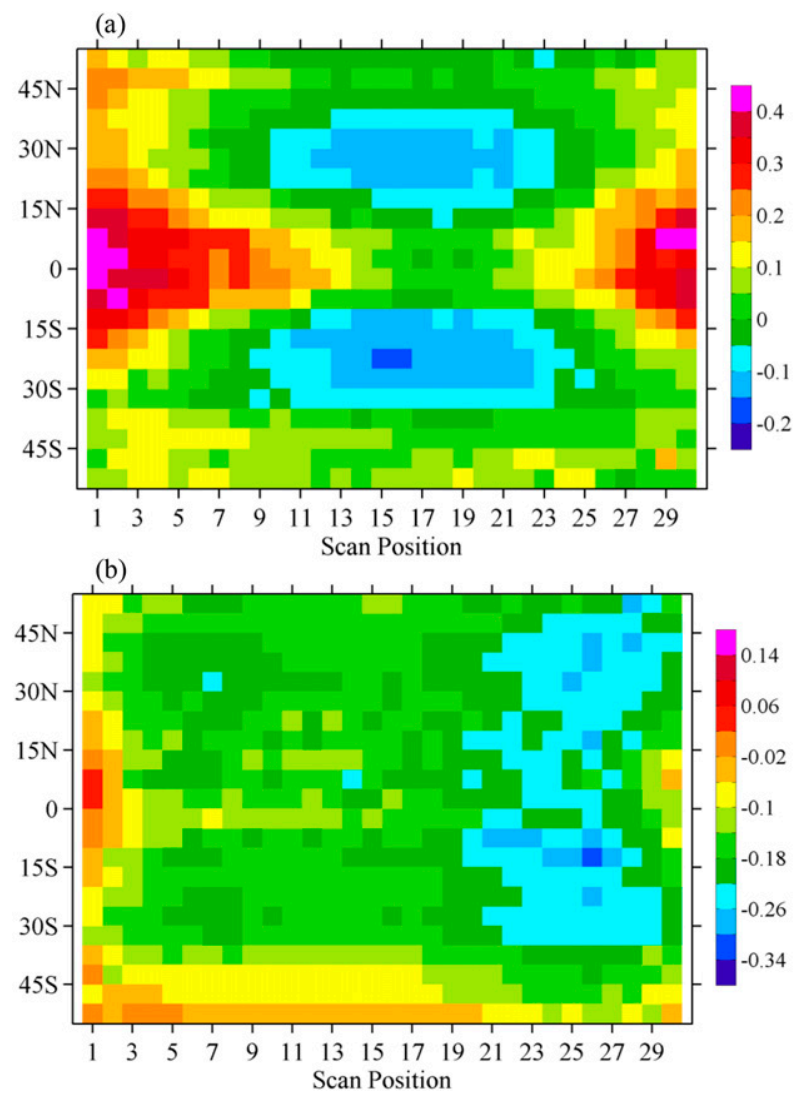

FIG. 2. $O-B$ brightness temperature biases for LWIR (a) channel $65\left(690 \mathrm{~cm}^{-1}, 85 \mathrm{hPa}\right)$ and (b) channel $88\left(704.375 \mathrm{~cm}^{-1}\right.$, $321 \mathrm{hPa}$ ) within $5^{\circ}$ latitudinal intervals and with respect to scan position ( $x$ axis) and latitude ( $y$ axis). Data are from 3 to 16 Sep 2015. The unit is $\mathrm{K}$.

simulations with observed brightness temperatures, linear temporal and bilinear spatial interpolations are employed.

Clear-sky CrIS pixels are identified using the collocated Visible Infrared Imaging Radiometer Suite (VIIRS) cloud mask (CM) product. As discussed by Kopp et al. (2014), the VIIRS CM product provides the cloud probability for each VIIRS pixel at four confidence levels: confidently cloudy, probably cloudy, probably clear, and confidently clear. Once the footprints of CrIS FOVs are computed according to the geolocation information (Wang et al. 2013), the clear fraction can be calculated using VIIRS CM data within each CrIS FOV footprint. Specifically, the clear fraction is defined as the ratio of VIIRS pixels flagged as confidently or probably clear to the total number of VIIRS pixels within the FOV. A $100 \%$ clear fraction threshold is applied to ensure a reliable estimation of clear-sky CrIS $O-B$ statistics. A more detailed description of CrIS simulations and the cloud-clearing procedure can be found in $\mathrm{Li}$ and Zou (2017). 
Based on the 2-week statistics, the $O-B$ biases (with respect to scan position and latitudinal band) of two representative CrIS LWIR channels are shown in Fig. 2. Before discussing results in Fig. 2, it is reminded that the $O-B$ biases contain both the observation bias $\left(\mu^{o}\right)$ and the NWP model bias $\left(\mu^{b}\right)$ since

$$
\begin{aligned}
\overline{O-B} & =\overline{(O-T)-(B-T)} \\
& =\overline{O-T}-\overline{B-T} \equiv \mu^{o}-\mu^{b},
\end{aligned}
$$

where $T$ represents the truth that we never have. In satellite DA, both the observation errors and background errors are assumed unbiased:

$$
\mu^{o} \equiv \overline{O-T}=0, \quad \mu^{b} \equiv \overline{B-T}=0 .
$$

If $\mu^{o} \neq 0$ and $\mu^{b} \neq 0$, the DA requires that the biases be subtracted from the observation and the background before DA:

$$
\begin{aligned}
\left(O-\mu^{o}\right)-\left(B-\mu^{b}\right) & =O-B-\left(\mu^{o}-\mu^{b}\right) \\
& =O-B-\overline{O-B} .
\end{aligned}
$$

By comparing Eqs. (5) and (7), we can conclude that an advantage of using $O-B$ statistics is to get rid of both the model bias and the observation bias without knowing the truth.

For the stratospheric $\mathrm{CO}_{2}$ channel $65\left(690 \mathrm{~cm}^{-1}\right.$, $85 \mathrm{hPa}$; Fig. 2a), biases generally increase with scan position. The biases are smallest in the midlatitudes around $30^{\circ}-15^{\circ} \mathrm{S}$ and $15^{\circ}-30^{\circ} \mathrm{N}$. For the tropospheric channel $88\left(704.375 \mathrm{~cm}^{-1}, 321 \mathrm{hPa}\right.$; Fig. $\left.2 \mathrm{~b}\right)$, latitudedependent and asymmetric scan-dependent biases are found in all latitudinal bands. As a cross-track sounder, the scan-varying features of biases can be attributed to variations in the optical path and the size of the FOV between different scan positions. In addition, $O-B$ biases usually depend on scene temperature and airmass conditions, which can explain the latitude-varying features of the biases. As discussed by Engelen and Bauer (2014) and Li and Zou (2017), the lack of a realistic distribution of $\mathrm{CO}_{2}$ concentrations in RTM simulations may also result in latitude-dependent biases for infrared $\mathrm{CO}_{2}$ channels. The example shown in Fig. 2 suggests that the $\mathrm{BC}$ of CrIS brightness temperatures requires an adequate consideration of both scan- and latitudedependent biases.

Figure 3 shows the global distribution of the lapse rate predictors for channels 65 and 88 at the ascending node on 15 September 2016. For stratospheric channel 65, values of predictor 5 (Fig. 3b) decrease with scan position and increase with latitude. On the contrary, values of predictor 4 (Fig. 3a) increase with scan position due to the squared sign in the formulation of this predictor. These relationships can be explained by the following reasons. First, at different latitudes, the atmospheric temperature lapse rate shows different features. As a result, the values of the predictors are assumed to represent latitudinal dependence. Second, since the lapse rate predictors are calculated based on the vertical integration of transmittance, which is associated with optical depth, variations in the optical path between different scan angles can lead to the scanvarying features of the lapse rate predictors. For tropospheric channel 88 , values of predictor 5 (Fig. 3d) decrease with latitude, while values of predictor 4 (Fig. 3c) decrease first and then increase as the latitude increases.

As we discussed earlier, the fourth and fifth predictors are the only two bias predictors that are airmass dependent. The second predictor is a function of scan angle, and the first and third predictors are held constant. The fourth and fifth predictors are correlated since both are functions of the lapse rate. Therefore, we examine the CrIS $O-B$ bias with the fourth and fifth predictors. Figure 4 displays the scatterplots of the fourth and fifth airmass predictors with respect to $O-B$ from four representative channels (a stratospheric channel, an upper-tropospheric channel, a lower-tropospheric channel, and a surface channel) under clear-sky conditions. To obtain a correct analysis of the validity of the airmass predictors 4 and 5 , the scan angle-dependent bias quantified by the predictor 2 is subtracted from the $O-B$ before creating Figs. 4 and 5. For stratospheric channel 65 , the correlation coefficients between $O-B$ biases and the fourth and fifth predictors are -0.31 and -0.53 , respectively (Figs. $4 a, b$ ). The relationship between the predictors and $O-B$ biases is not significantly linear. For the upper-tropospheric channel 88, correlation coefficients between the fourth and fifth predictors and $O-B$ biases are close to 0 (Figs. 4d,e). Values of predictor 5 monotonically increase with latitude, but $O-B$ biases show little latitudinal change. This leads to no linear relationship between the predictors and $O-B$ biases for channel 88 . Similar characteristics are also found in the lowertropospheric channel 145 (Figs. 4g,h) and the surfacesensitive channel 392 (Figs. 4j,k). We also investigate the linear combination of predictor 4 and predictor 5 as a whole lapse rate correction term, expressed as $\beta_{4} \times P_{4}+\beta_{5} \times P_{5}$, and its dependence on the $O-B$ biases (Figs. 4c,f,i,l). For each of the four channels examined, the relationships between the combined lapse rate term and $O-B$ biases are similar to 

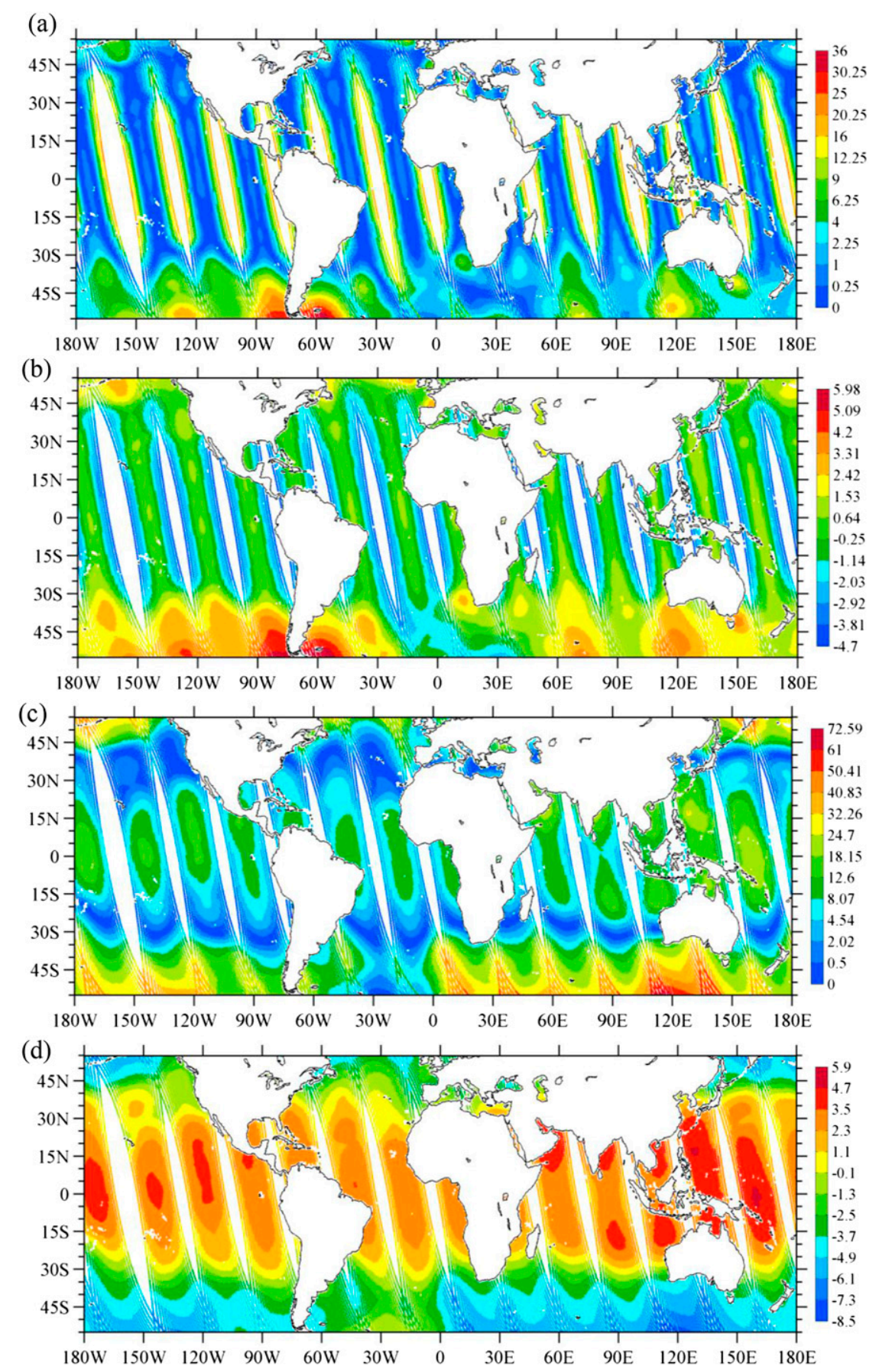

FIG. 3. Distributions of the (a),(c) fourth and (b),(d) fifth airmass predictors for (a),(b) channel $65\left(690 \mathrm{~cm}^{-1}, 85 \mathrm{hPa}\right)$ and (c), (d) channel $88\left(704.375 \mathrm{~cm}^{-1}, 321 \mathrm{hPa}\right)$ at the ascending node on 15 Sep 2016.

that between the fifth predictor and $O-B$ biases (Figs. 4b,e,h,k). Although the use of a high-order lapse rate in the fourth predictor is designed to account for the nonlinear effect, results suggest that the fifth predictor dominates the contribution representing CrIS $O-B$ biases for most of the channels.
Figure 5 shows the correlation coefficients and the corresponding coefficient of determination $\left(R^{2}\right)$ values among the fourth predictor (black curve), the fifth predictor (red curve), the linear combination of the fourth predictor and the fifth predictor 5 (blue curve), and the $O-B$ biases for all CrIS LWIR channels that are 

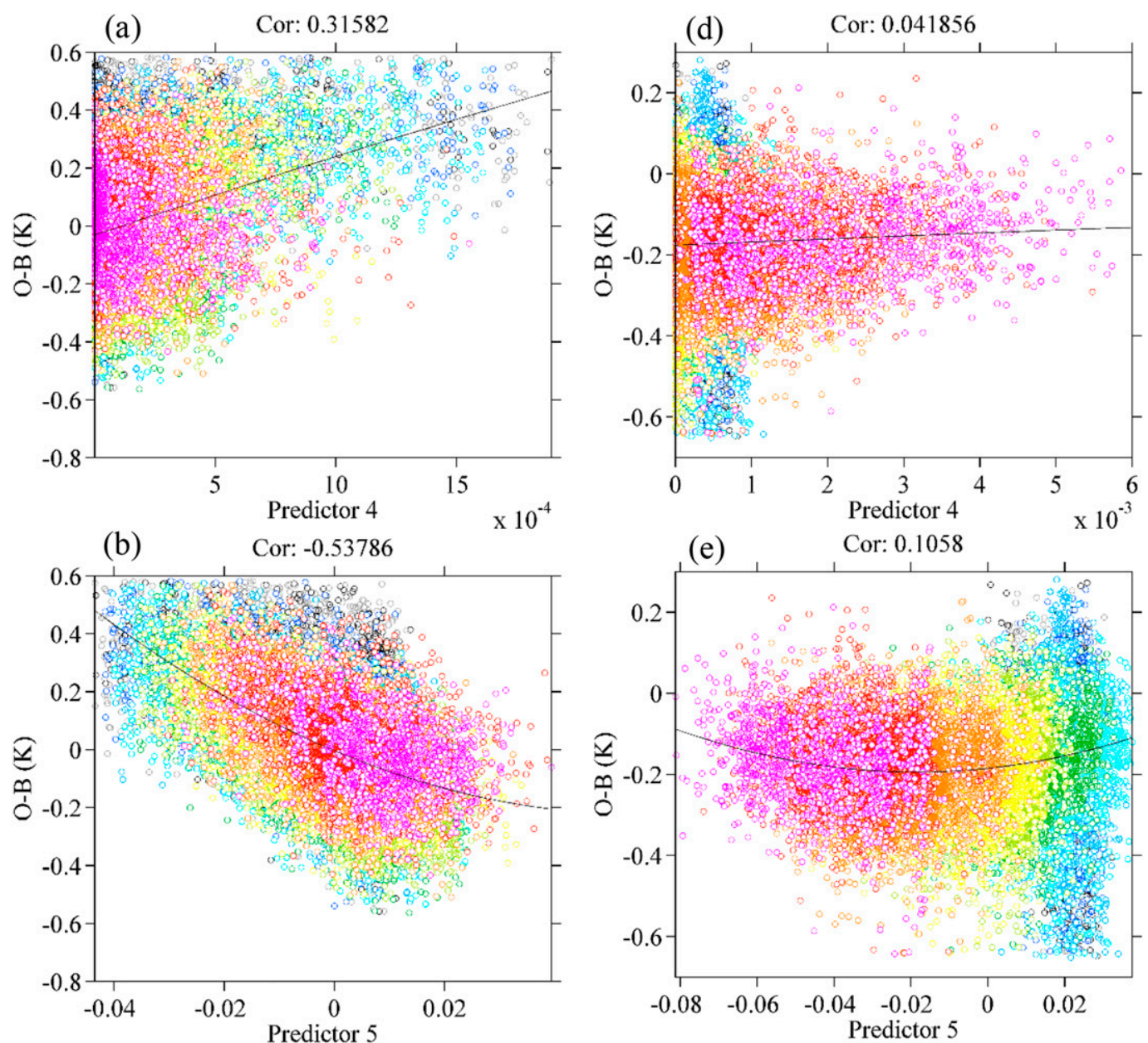

(c)

Predictor 5
Cor: 0.52622
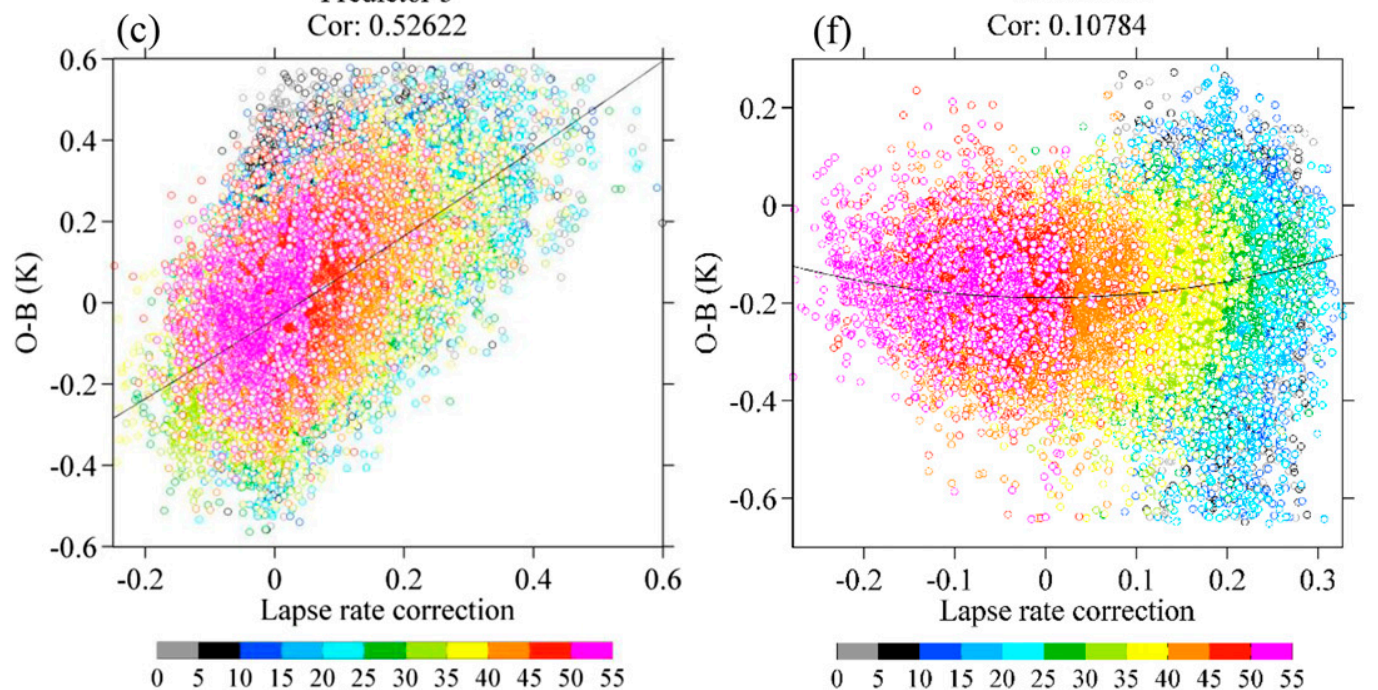

FIG. 4. Scatterplots of (a),(d),(g),(j) airmass predictor 4, (b),(e),(h),(k) predictor 5, and (c),(f),(i),(l) the sum of lapse rate correction term $\left(\beta_{4} \times P_{4}+\beta_{5} \times P_{5}\right)$ with respect to $O-B$ for clear-sky data of (a)-(c) stratospheric channel $65(85 \mathrm{hPa}),(\mathrm{d})-(\mathrm{f})$ upper-tropospheric channel $88(321 \mathrm{hPa}),(\mathrm{g})$-(i) lower-tropospheric channel 145 $(749 \mathrm{hPa})$, and (j)-(l) surface channel 392. Data are from 3 to 16 Sep 2015. The different colors represent latitudes, and the correlation between $O-B$ and the airmass predictors is given at the top of each panel. Black curves show the second-order polynomial fitting. The BC contributed by predictor $2\left(\beta_{2} \times P_{2}\right)$ is subtracted from the $O-B$. 

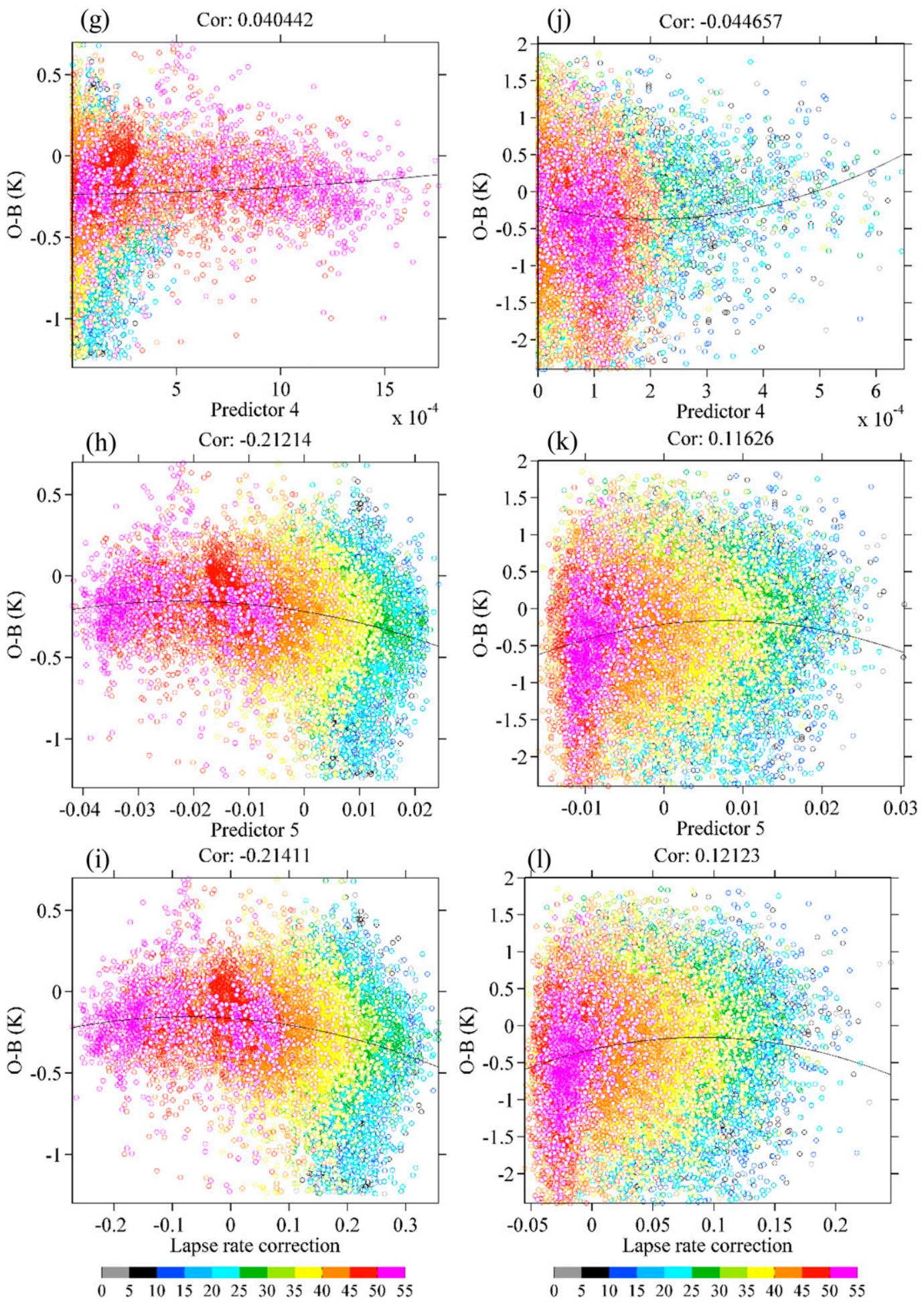

FIG. 4. (Continued)

actively used in the GSI system. For predictor 5, absolute values of the correlation coefficient are less than 0.65 for stratospheric channels and much lower for the remaining channels. For predictor 4, absolute values of the correlation coefficient are no more than 0.4 (Fig. 5a). These results are also supported by the corresponding $R^{2}$ values (Fig. 5b). It reveals that neither the individual airmass predictors nor the linear combination of the 
(a) Wave Number $\left(\mathrm{cm}^{-1}\right)$

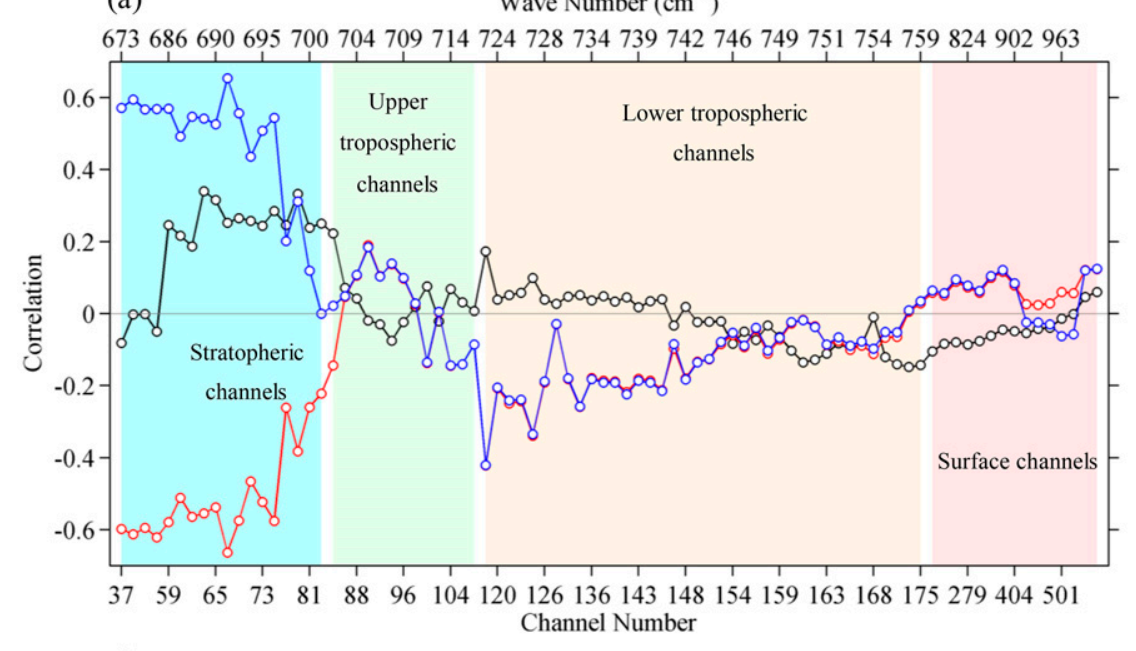

(b)

Wave Number $\left(\mathrm{cm}^{-1}\right)$

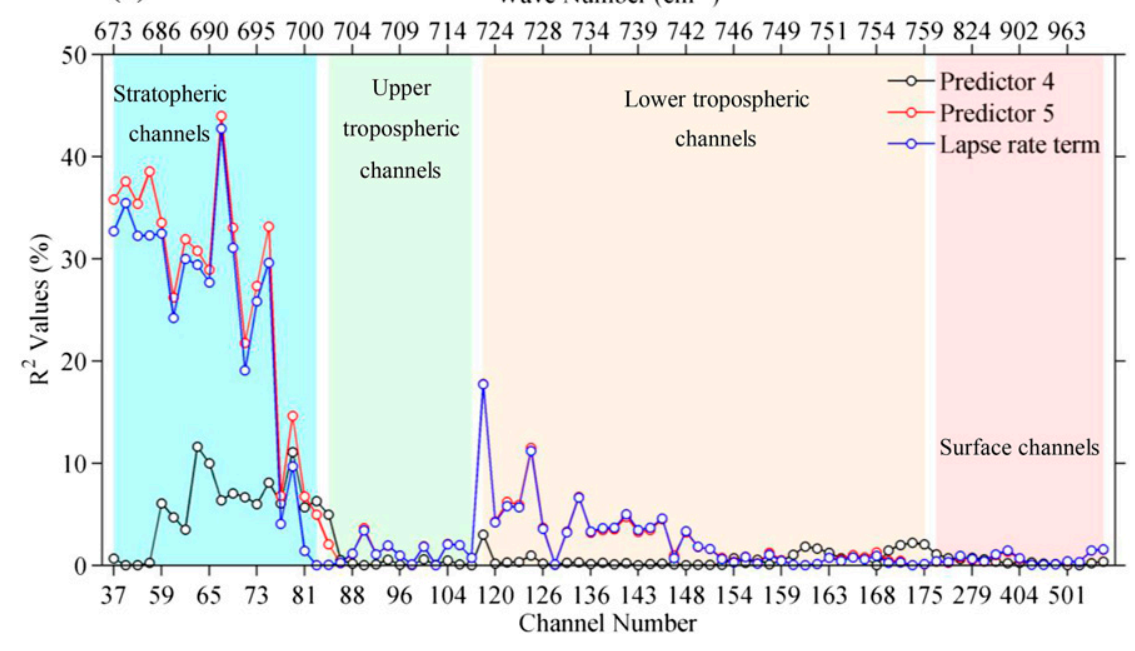

FIG. 5. (a) Correlations between $O-B$ and airmass predictor 4 (black line), correlations between $O-B$ and airmass predictor 5 (red line), and correlations between $O-B$ and the lapse rate correction term (blue line) estimated from clear-sky data for the 84 LWIR channels. (b) The associated coefficient of determination $\left(R^{2}\right)$ values. Data are from 3 to 16 Sep 2015.

predictors is linear correlated to the biases of the CrIS channels. Therefore, the linear combination of airmass predictors may be inadequate for modeling CrIS biases.

To better illustrate the contribution of lapse rate predictors to the CrIS BC, mean values of predictor 4 , predictor 5 , and the combined lapse rate correction term $\left(\beta_{4} \times P_{4}+\beta_{5} \times P_{5}\right)$ under clear-sky conditions are plotted with respect to scan position and latitude for channel $65(85 \mathrm{hPa})$ and channel $88(321 \mathrm{hPa})$ in Fig. 6. Data are from the same period as that of $O-B$ biases presented in Fig. 2. For individual predictors (Figs. 6a-d), the scan-varying and latitude-varying features obtained from the 2-week mean value are consistent with the spatial distribution on the specific day shown in Fig. 3. For channel 65, focusing on the Northern Hemisphere, the lapse rate correction term shows little latitudinal variation (Fig. 6e), but the $O-B$ biases in the midlatitude region (around $20^{\circ}-45^{\circ} \mathrm{N}$ ) are smaller than at other latitudes (Fig. 2a). This suggests that the airmass lapse rate correction may result in an insufficient latitude-dependent bias correction in the midlatitude region. For channel 88, the lapse rate correction term decreases with latitude especially when the latitude is higher than $20^{\circ} \mathrm{N}$. However, the CrIS $O-B$ biases change little as the latitude increases (Fig. 2b). As a result, the contribution of the airmass lapse rate term to the latitude-dependent $\mathrm{BC}$ of this channel is problematic when the latitude is higher than $20^{\circ} \mathrm{N}$. 
(a)

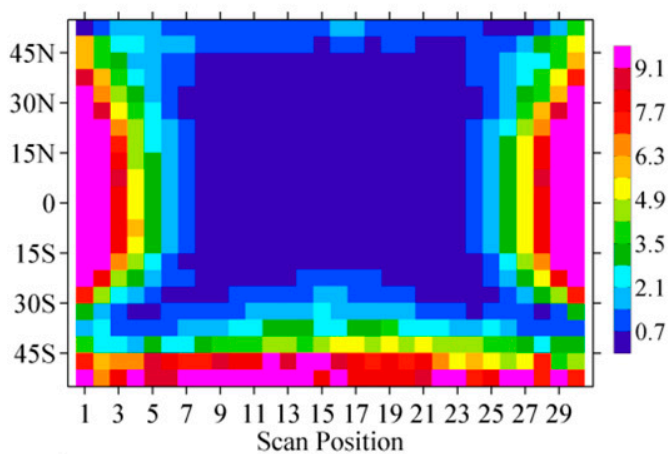

(c)

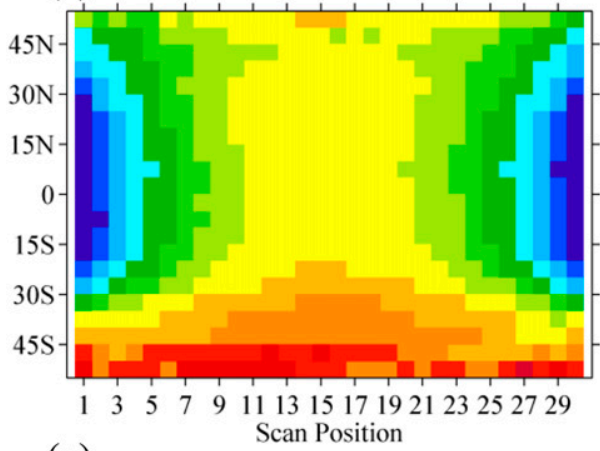

(e)

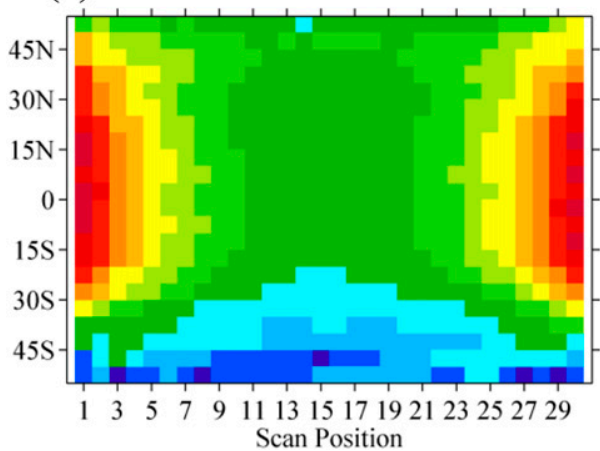

(b)

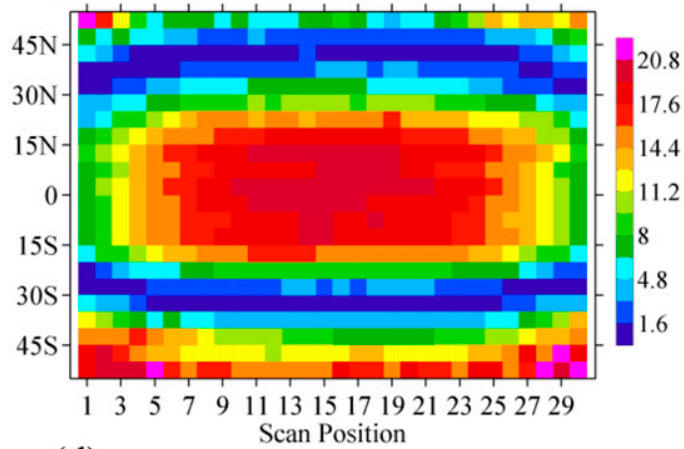

(d)

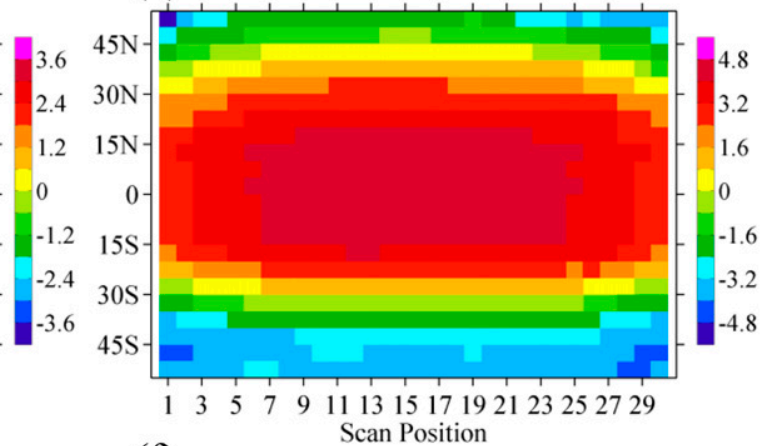

(f)

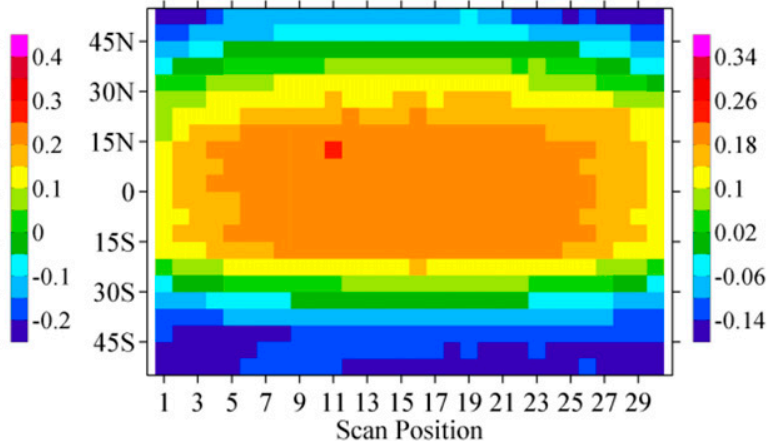

FIG. 6. Mean values of the (a),(b) fourth and (c),(d) fifth predictors and (e),(f) the lapse rate correction term $\left(\beta_{4} \times P_{4}+\beta_{5} \times P_{5}\right)$ for LWIR (left) channel $65\left(690 \mathrm{~cm}^{-1}, 85 \mathrm{hPa}\right)$ and (right) channel $88\left(704.375 \mathrm{~cm}^{-1}, 321 \mathrm{hPa}\right)$ within $5^{\circ}$ latitudinal intervals and with respect to scan position ( $x$ axis) and latitude ( $y$ axis). Data are from 3 to 16 Sep 2015.

\section{Assimilation experiment configurations}

\section{a. A modified BC scheme}

As discussed in section 3, the particular choice of GSI airmass predictors is probably insufficient for representing CrIS biases. To avoid the predictors-based BC algorithm, a simpler modified BC scheme based on the sampling of $O-B$ departures from previous GSI cycles is proposed for CrIS DA. Specifically, considering the scan-dependent and state-dependent components of CrIS biases, $O-B$ departures $\mu_{\theta, \varphi}$ are sampled within the individual boxes seen in Fig. 2. These departures are expressed as

$$
\mu_{\theta, \varphi}=\left.\overline{O-B}\right|_{\theta, \varphi},
$$

where $\mu$ stands for the $O-B$ departures, and $O$ and $B$ are observations and model simulations from previous GSI cycles, respectively. The variables $\theta$ and $\varphi$ stand for scan angle and latitude, respectively.

Also, taking the time-varying features of the biases into account, at each assimilation time, the bias correction term $\mu_{\theta, \varphi}$ is calculated based on the equally weighted moving average of the background departures from data (i.e., $O-B$ ) during the 2 weeks prior to the assimilation time. The data from the earlier cycles on the same day are also included in calculating $\mu_{\theta, \varphi}$. After the bias 


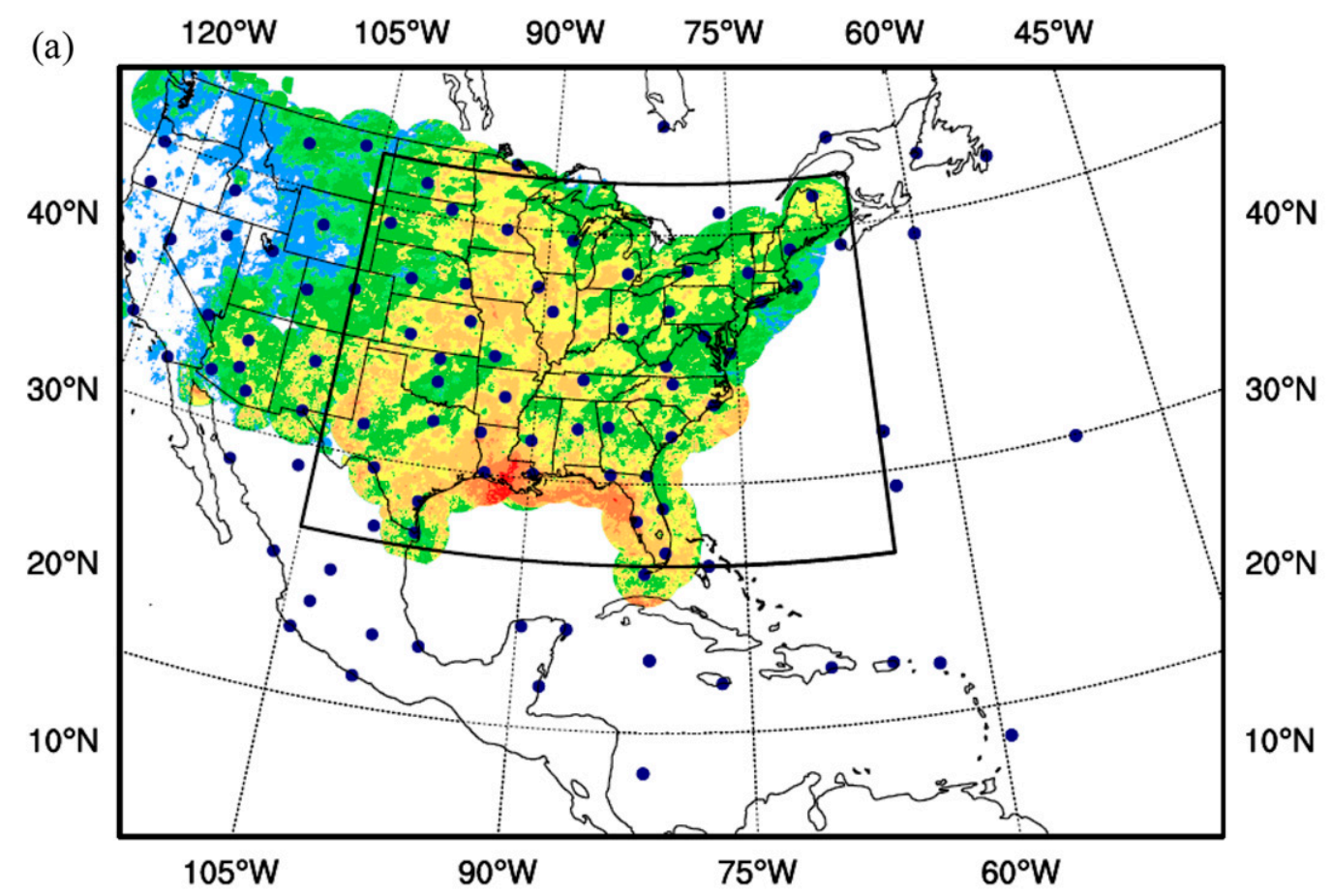

(b)

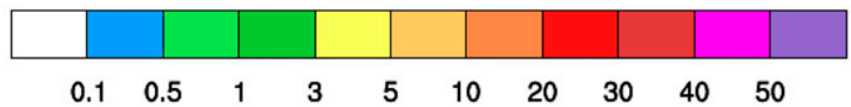

Initial condition:

Initial condition:

GFS analysis

GFS analysis
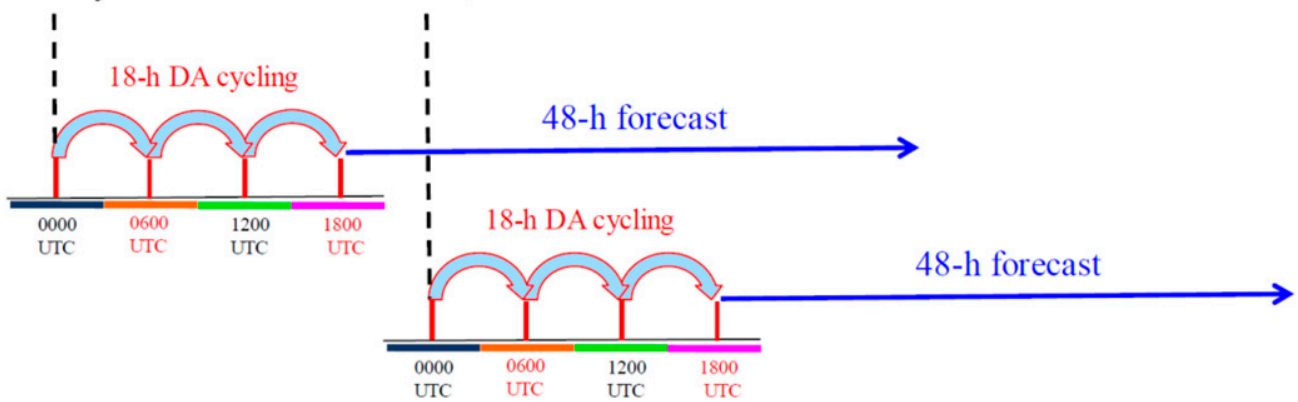

FIG. 7. (a) The WRF forecasting domain, monthly mean precipitation in August from NCEP multisensor observations (color shaded; unit: $\mathrm{mm}$ ), and a snapshot of the radiosonde network at 1200 UTC 23 Aug 2016 (blue dots) used to verify forecast results. The inner box shows the validation area used for 1-month predicted precipitation. (b) Schematic illustration of the 18-h DA cycling and the 48-h forecast experiments initialized from 0000 UTC for the 1-month experiment.

correction, the modified observation operator in the cost function is equal to

$$
\tilde{H}(\mathbf{x})=H(\mathbf{x})+\mu_{\theta, \varphi} .
$$

\section{b. Overview of NCEP GSI and CrIS radiance DA}

The NCEP GSI system, version 3.3, three-dimensional variational DA system (Wu et al. 2002) is employed in this study. The system solves the satellite radiance DA problem by minimizing the following cost function:

$$
\begin{aligned}
J(\mathbf{x}, \beta)= & \frac{1}{2}\left(\mathbf{x}-\mathbf{x}_{b}\right)^{\mathrm{T}} \mathbf{B}^{-1}\left(\mathbf{x}-\mathbf{x}_{b}\right) \\
& +\frac{1}{2}\left[\mathbf{y}_{o}-\tilde{H}(\mathbf{x}, \beta)\right]^{\mathrm{T}} \mathbf{R}^{-1}\left[\mathbf{y}_{o}-\tilde{H}(\mathbf{x}, \beta)\right] \\
& +\frac{1}{2}\left(\beta-\beta_{b}\right)^{\mathrm{T}} \mathbf{B}_{\beta}{ }^{-1}\left(\beta-\beta_{b}\right),
\end{aligned}
$$


where $\mathbf{x}$ is the analysis, $\mathbf{x}_{b}$ the background, $\mathbf{y}_{o}$ the observation, $\mathbf{B}$ the background error covariances, and $\mathbf{R}$ the observation error covariances. The variational $\mathrm{BC}$ scheme (VarBC; Dee 2004; Auligné et al. 2007; Zhu et al. 2014a) is employed within the GSI system to perform the airmass BC. In Eq. (10), $\beta$ is the bias-predictor coefficient, $\beta_{b}$ is the prior estimate of $\beta$, and $\mathbf{B}_{\beta}$ is the block-diagonal background error covariance for $\beta$. For the direct assimilation of satellite radiance data in the GSI system, the fast CRTM is used as the observation operator $H$, which calculates model-simulated brightness temperatures based on the atmospheric profile input.

In the default GSI variational airmass BC scheme, the bias-predictor coefficients $\beta$ are updated simultaneously with the state variables $\mathbf{x}$, and the latest bias-predictor coefficients are used to obtain the modified observation operator $\tilde{H}(\mathbf{x}, \beta)$ [Eq. (4)]. However, in the modified $\mathrm{BC}$ scheme proposed in section $4 \mathrm{a}$, since the airmass $\mathrm{BC}$ and VarBC are turned off for CrIS radiances, the constraint term $1 / 2\left(\beta-\beta_{b}\right)^{\mathrm{T}} \mathbf{B}_{\beta}{ }^{-1}\left(\beta-\beta_{b}\right)$ associated with $\operatorname{VarBC}$ is not included in the cost function. The modified observation operator $\tilde{H}(\mathbf{x})$ is defined by Eq. (9).

In addition to $\mathrm{BC}$, quality control (QC) is another important procedure to do before radiance assimilation. In this study, the existing GSI quality control procedures on cloud detection (Eyre and Menzel 1989), gross check, surface emissivity check, and observation error adjustments are employed.

\section{c. Experiment setup}

A 1-month analysis/forecast experiment is conducted during the warm season of the North American continent. Most of the summertime precipitation is located in eastern and central United States (Fig. 7a). These areas have favorable conditions for developing convective precipitation, supported by the warm and moist air from the Gulf of Mexico and the Atlantic Ocean. Also, the southeastern region often experiences hurricanes making landfall, resulting in monthly average precipitation amounts that are much higher than in the western United States.

Four parallel DA experiments (Table 2) are carried out to evaluate the impact of CrIS DA with two different $\mathrm{BC}$ schemes in a regional model. The first benchmark control experiment, CTL, assimilates conventional observations and Advanced Microwave Sounding Unit-A (AMSU-A) data from NOAA-15/18/19 and MetOp-A/B satellites. The second experiment, EXP1, assimilates the same observations as CTL plus clear-sky CrIS radiances using the GSI default airmass BC scheme [Eq. (3)]. The third experiment, EXP2, is the same as EXP1, except for applying the modified BC scheme [Eq. (8)] for CrIS channels. The fourth experiment, EXP3, is similar to EXP2, except that the BC term is calculated based on the moving average of observation-minus-analysis $(O-A)$ statistics, rather than $O-B$ samples, from data in the previous 2 weeks. The four parallel experiments are carried out for 1 month, covering the period from 1 to 31 August 2016. It is noted that EXP3 is only included in section 5a for discussing the analysis/forecast results from the 1-month experiments. In other places, the term "modified BC scheme" refers to EXP2 unless otherwise stated.

For each experiment, the cycled DA has a cold start using the GFS analysis as the initial condition of the WRF Model every day at 0000 UTC and assimilates observations at 0600,1200, and 1800 UTC. After the three analysis cycles, a 48-h forecast is launched (Fig. $7 b$ ). The GFS global analysis with $0.25^{\circ}$ grids is used to provide the initial and boundary conditions for all experiments. Furthermore, since both BC schemes require information from previous cycles, we start the

TABLE 2. Experimental design for 1-month (1-31 Aug 2016) cycled assimilation and forecasting experiments.

\begin{tabular}{|c|c|c|c|}
\hline Experiment & Description & Analysis cycles & Forecast period \\
\hline CTL & $\begin{array}{l}\text { GFS data }+ \text { conventional data }+N O A A- \\
\text { 15/18/19 AMSU-A }+ \text { MetOp }-A / B \\
\text { AMSU-A }\end{array}$ & $\begin{array}{l}\text { 6-h preforecast starting at } 0000 \text { UTC, with } \\
\text { three } 6 \text {-h cycled analyses at } 0600,1200 \text {, } \\
\text { and } 1800 \text { UTC }\end{array}$ & 48-h forecast after analysis cycles \\
\hline EXP1 & $\begin{array}{c}\text { GFS data }+ \text { conventional data }+N O A A-15 / \\
\text { 18/19 AMSU-A }+ \text { MetOp- } A / B \text { AMSU- } \\
\text { A }+ \text { CrIS (GSI default BC scheme) }\end{array}$ & & \\
\hline EXP2 & $\begin{array}{l}\text { GFS data + conventional data }+ \text { NOAA- } \\
\text { 15/18/19 AMSU-A + MetOp-A/B } \\
\text { AMSU-A + CrIS (modified BC } \\
\text { scheme) }\end{array}$ & & \\
\hline EXP3 & $\begin{array}{l}\text { Same as EXP2, except for using the } \\
\text { moving average of } O-A \text {, rather than } \\
O-B \text {, as the BC term }\end{array}$ & & \\
\hline
\end{tabular}


(a)
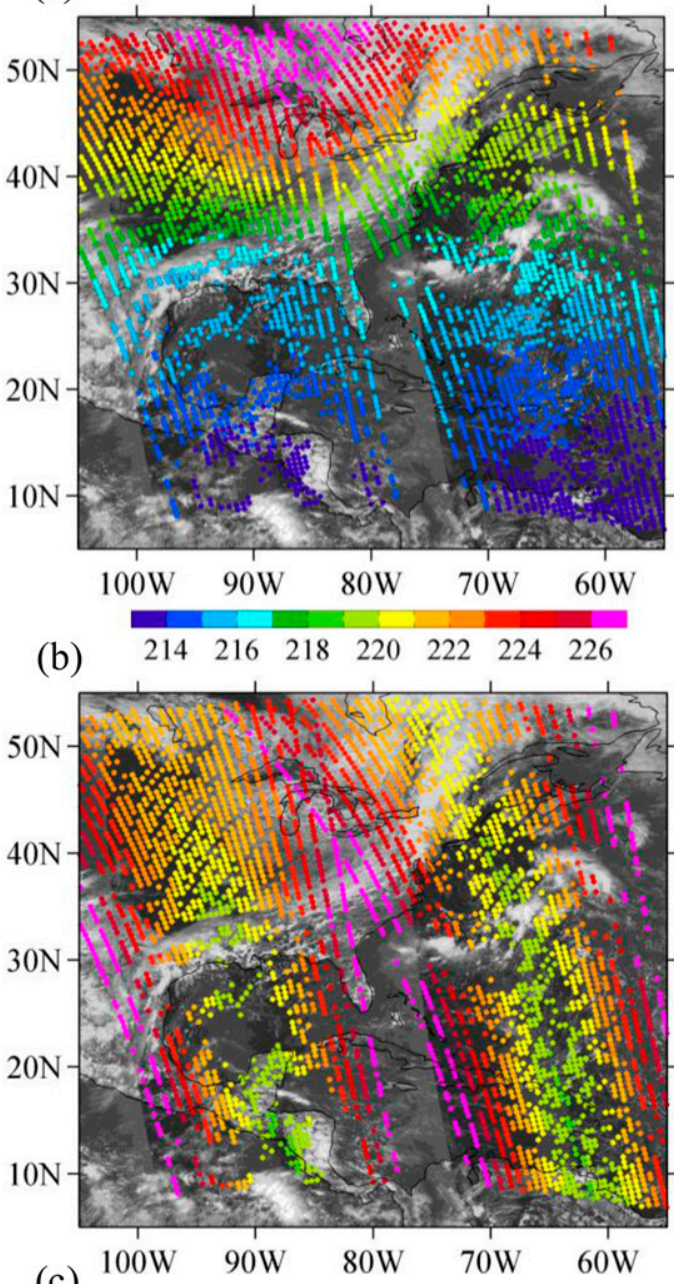

(c)

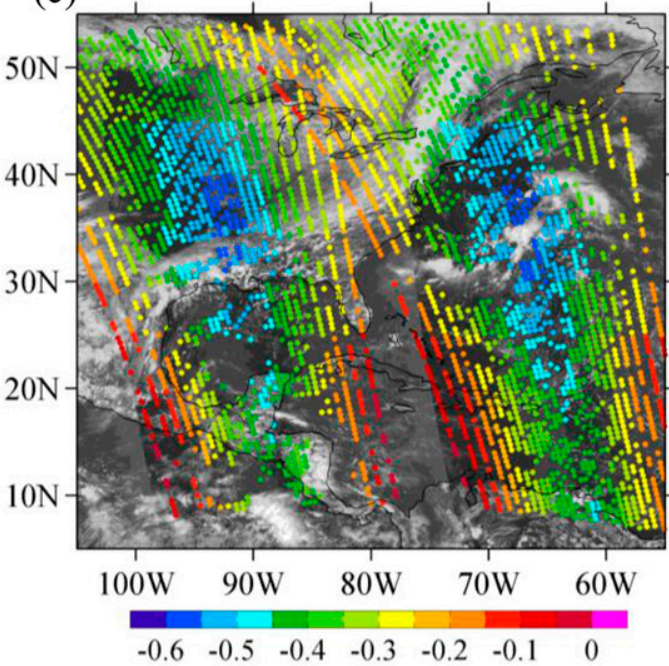

(d)

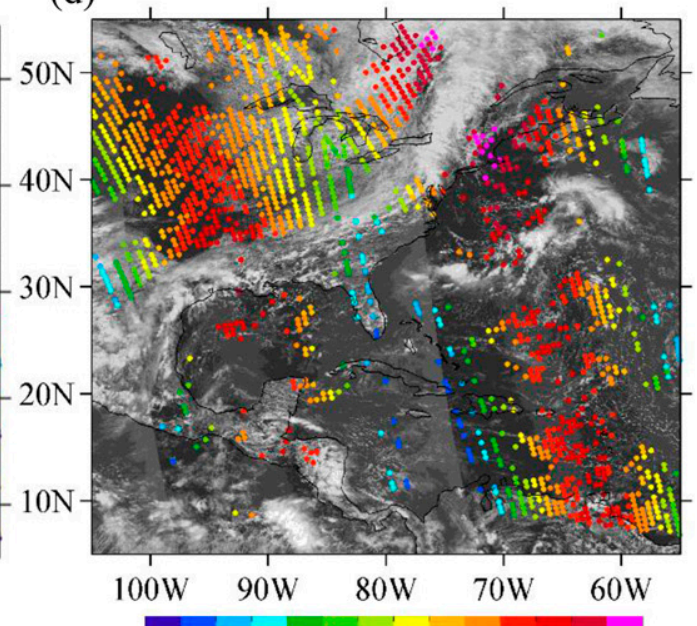

(e)

223.5225226 .5228229 .5231232 .5
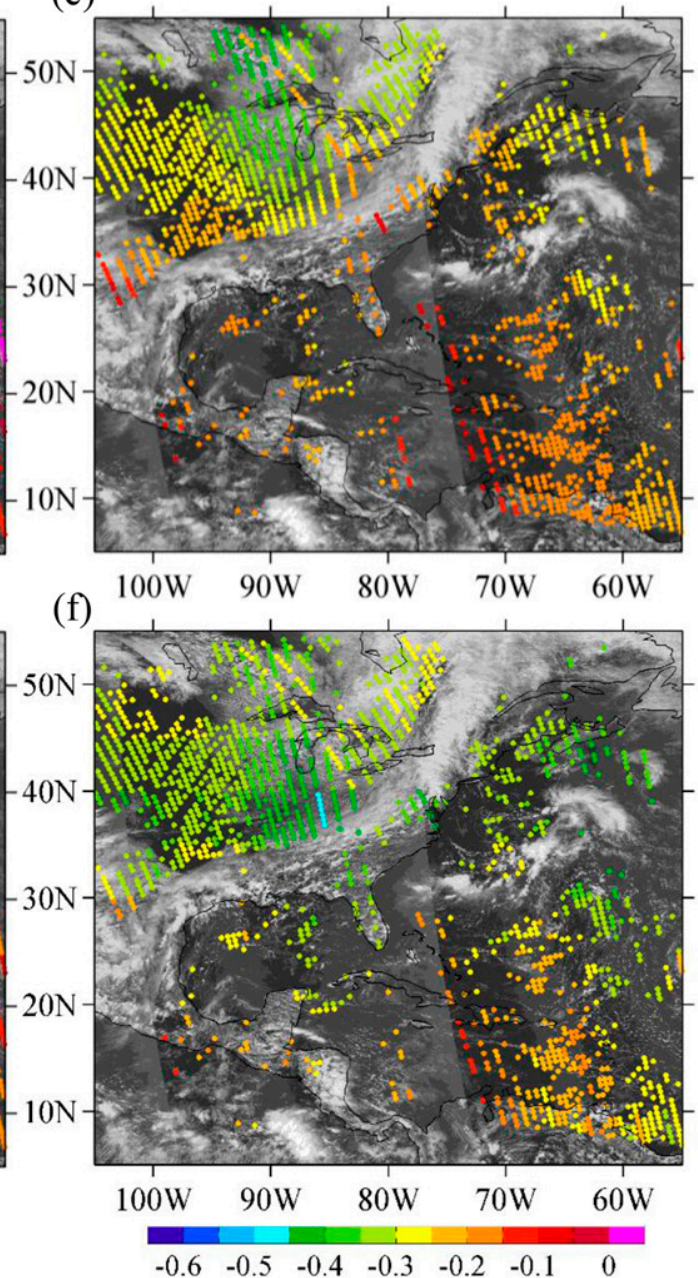

FIG. 8. Spatial distributions of (top) the CrIS brightness temperature, (middle) the GSI default BC, and (bottom) the modified BC for (a)-(c) channel 67 (122 hPa) and (d)-(f) channel 88 ( $321 \mathrm{hPa})$, overlapped by M1 visible band VIIRS reflectances (black and white background) at $\sim 1800$ UTC 21 Aug 2016. Only CrIS pixels that passed the QC process are shown. 
(a)

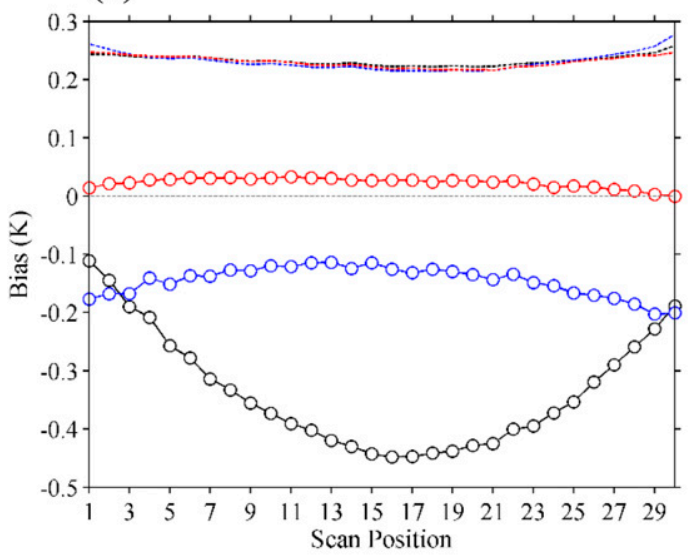

(c)

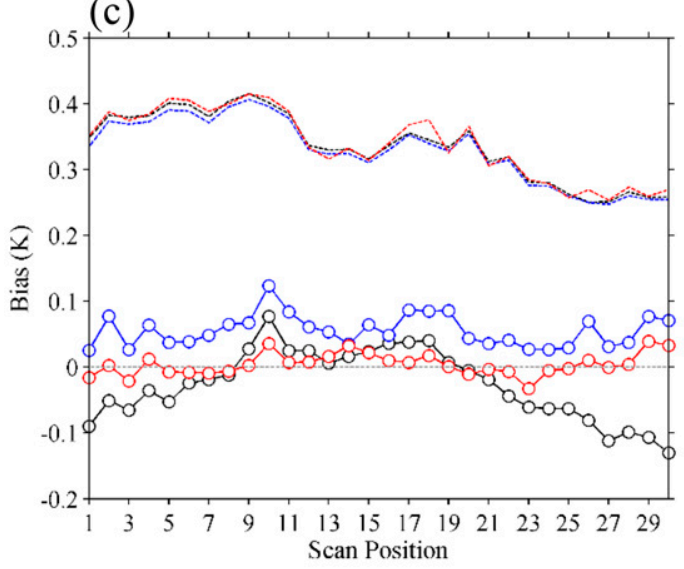

(b)

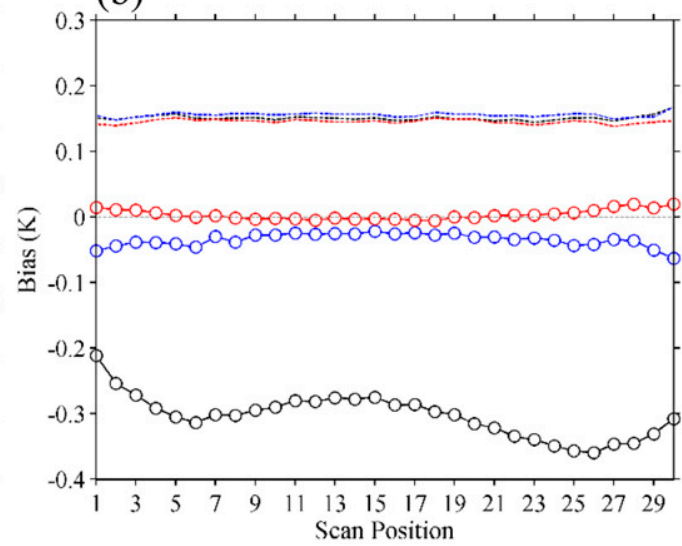

(d)

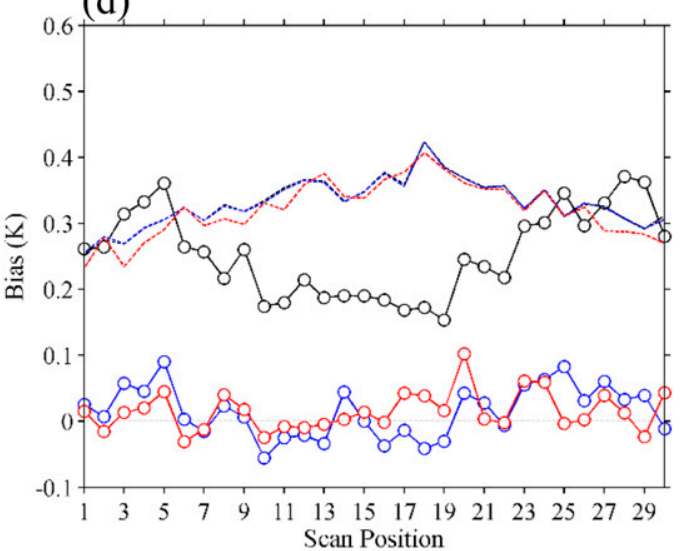

$\multimap-\mathrm{NoBC}$

$\multimap-\mathrm{AirBC}$

$-0-$ ModBC

FIG. 9. The scan variations of $O-B$ biases without the BC (black curve), with the airmass BC (blue curve), and with the modified $\mathrm{BC}$ (red curve) sampled from the 1-month assimilation experiments for (a) stratospheric channel $67(122 \mathrm{hPa}),(\mathrm{b})$ upper-tropospheric channel $88(321 \mathrm{hPa})$, (c) lower-tropospheric channel $137(749 \mathrm{hPa})$, and (d) surface channel 392. Only data that passed the GSI QC process are used. The standard deviations of $O-B$ are shown as dashed lines.

experiments from 1 July 2016, which is 1 month ahead of the investigation period. For the variational airmass BC scheme, the bias-predictor coefficients at each cycle are inherited from the previous cycles of the Advanced Research version of the Weather Research and Forecasting (WRF-ARW) Model. For the modified BC scheme, $O-B$ departures from the previous 2 weeks are prepared.

The WRF-ARW, version 3.8, is employed as the forecasting model. The domain is configured with $750 \times 500$ horizontal grid points with a $10-\mathrm{km}$ resolution, covering the continental United States (Fig. 7a). There are 61 vertical levels from the surface to $1 \mathrm{hPa}$. The physics options include the WRF singlemoment 6-class microphysics (Hong and Lim 2006), the Kain-Fritsch cumulus (Kain and Fritsch 1990; Kain 2004), the Rapid Radiative Transfer Model longwave radiation (Mlawer et al. 1997), the Dudhia shortwave radiation (Dudhia 1989), the MoninObukhov surface layer (Monin and Obukhov 1954), the Noah land surface (Chen and Dudhia 2001), and the Yonsei University planetary boundary layer (Noh et al. 2003) schemes.

\section{Impact of CrIS DA}

\section{a. Analysis/forecast results from 1-month experiments}

Figure 8 shows the spatial distributions of the biases $\mu_{\theta, \varphi}$ [Eq. (8)] calculated using the modified BC scheme and the biases $\mu$ [Eq. (3)] calculated using the traditional airmass BC scheme for channel $67(122 \mathrm{hPa})$ and channel $88(321 \mathrm{hPa})$ at $1800 \mathrm{UTC} 21$ August 2016, along with 
(a)

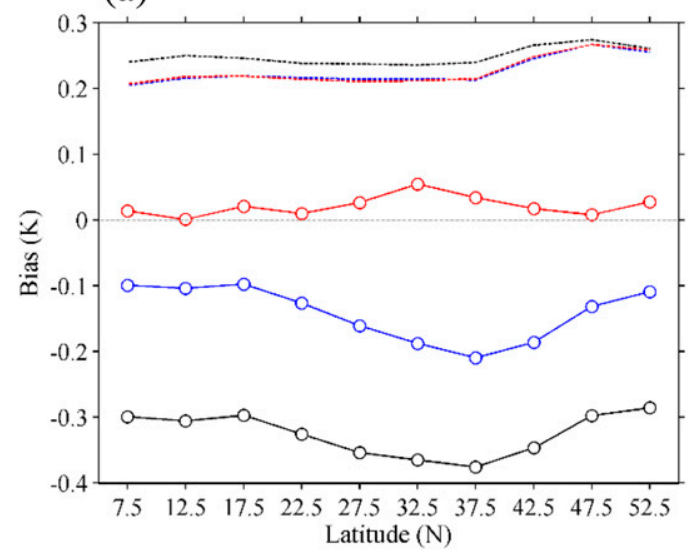

(c)

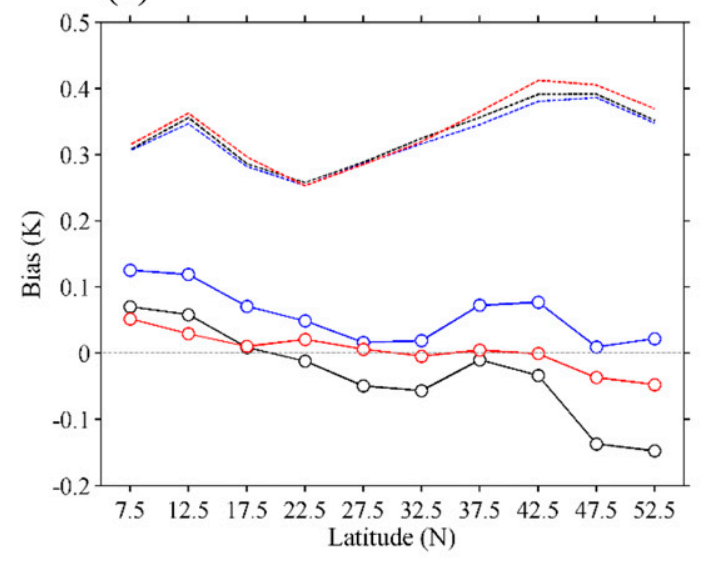

(b)

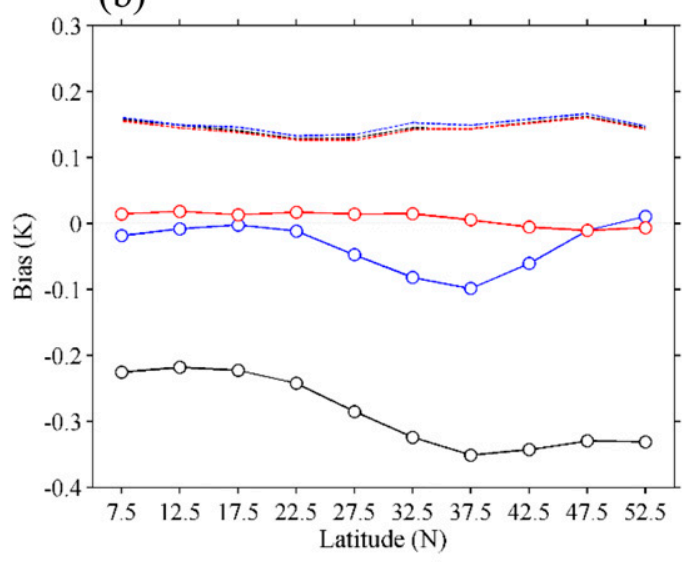

(d)

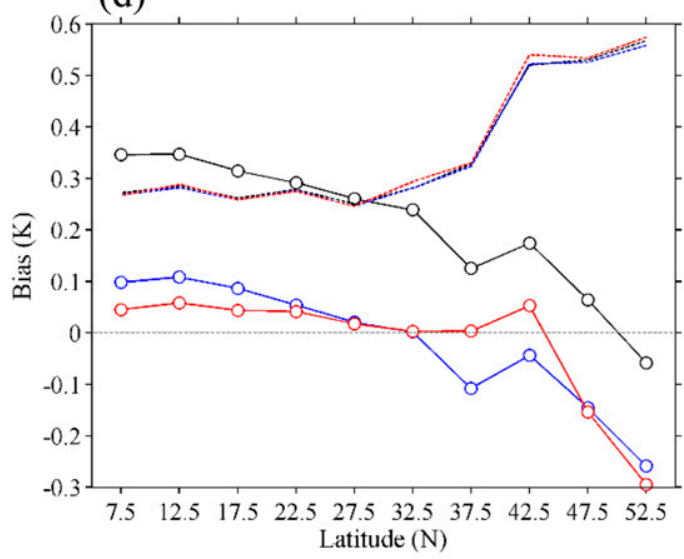

$\multimap-\mathrm{NoBC}$

$\multimap$ AirBC

$-\circ$ ModBC

FIG. 10. As in Fig. 9, but for the latitudinal variations of $O-B$ biases.

the corresponding brightness temperatures. For this single assimilation time, the modified $\mathrm{BC}$ term $\mu_{\theta, \varphi}$ is calculated based on the $O-B$ departures of the previous GSI analysis cycles from 7 to 20 August. For the stratospheric channel 67 , the modified $\mathrm{BC}$ terms $\mu_{\theta, \varphi}$ (Fig. 8c) are generally smaller than the traditional BC terms $\mu$ (Fig. $8 \mathrm{~b}$ ). Also, the latitudinal variation of the modified BC terms $\mu_{\theta, \varphi}$ (Fig. 8c) is more obvious than the traditional $\mathrm{BC}$ terms $\mu$ (Fig. $8 \mathrm{~b}$ ), especially in the midlatitudes (around $20^{\circ}-45^{\circ} \mathrm{N}$ ). For the tropospheric channel 88, the modified BC terms $\mu_{\theta, \varphi}$ (Fig. 8f) are smaller than the traditional BC terms $\mu$ (Fig. 8e) at high latitudes. Regarding CrIS QC, for the tropospheric channel that is affected by clouds, cloudy radiance data over both oceans and land can be generally identified by the GSI infrared cloud detection method (Eyre and Menzel 1989), although some clear-sky pixels are also removed (Fig. 8d).

Before evaluating the impact of CrIS radiance DA, the effectiveness of CrIS BC by the two different schemes is demonstrated in Figs. 9-11. Figure 9 shows the scan variations of $O-B$ biases before and after BC for four representative channels: stratospheric channel 67 (122 hPa), upper-tropospheric channel 88 (Fig. 9b), lower-tropospheric channel 137 (Fig. 9c), and surface channel 392 (Fig. 9d). Without the BC, the mean biases of $O-B$ show obvious scan-dependent features for all channels considered. In general, the $O-B$ mean biases are significantly reduced after either the airmass $\mathrm{BC}$ or the modified $\mathrm{BC}$ is done. However, residual scandependent biases are still found after the airmass BC is done. The modified BC scheme performs better in reducing the scan-dependent biases, especially for stratospheric channel 67 (Fig. 9a) and lower-tropospheric channel 137 (Fig. 9c).

Figure 10 presents the latitudinal variations in $O-B$ biases before and after $\mathrm{BC}$ for the four representative channels. Residual latitude-dependent biases still remain for all channels after the airmass BC is done, especially at midlatitudes. This is not surprising because 


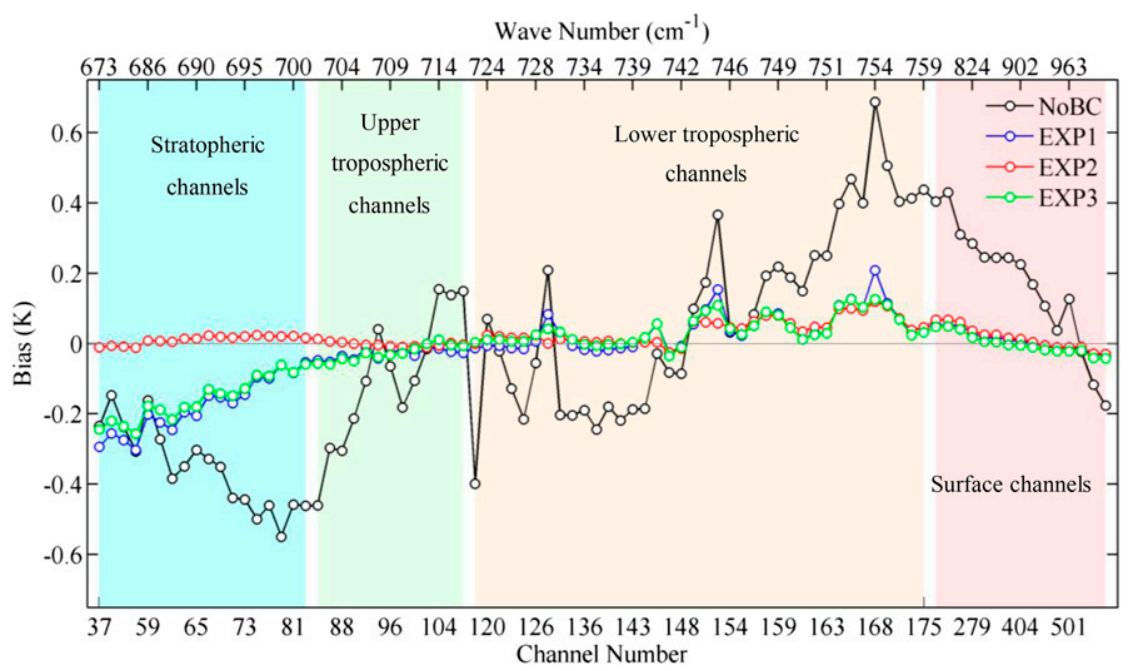

FIG. 11. Mean $O-B$ biases for 84 LWIR assimilation channels without the BC (black curve), with the airmass BC (blue curve), with the modified BC (red curve), and with the modified BC tested in a configuration where the bias is based on the running average of $O-A$ from the previous 2-week cycles (green curve). The results are sampled from the 1-month assimilation experiments. Only data that passed the GSI QC process are used.

the lapse rate predictors cannot well represent the latitude-dependent characteristics of $O-B$ departures for CrIS channels (Figs. 4, 6).

Figure 11 shows mean $O-B$ biases for all the 84 LWIR channels before and after BC. The modified BC scheme reduces $O-B$ biases to less than $\pm 0.1 \mathrm{~K}$ for all channels, while the airmass BC scheme fails to effectively reduce the $O-B$ biases in the stratospheric channels and some lower-tropospheric channels. Results from Figs. 9-11 suggest that the modified $\mathrm{BC}$ scheme performs better than the traditional airmass $\mathrm{BC}$ scheme in correcting CrIS radiance biases.

A possible reason for the negative biases in stratospheric channels after the airmass $\mathrm{BC}$ is that it comes from the negative biases of the simulated brightness temperatures between the model analysis $(A)$ and the model background ( $B$; i.e., $A-B$; Fig. 12 ) in the regional model. In fact, the satellite radiance bias is (a)

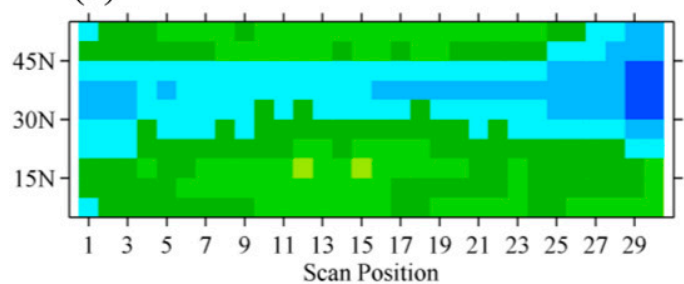

(b)

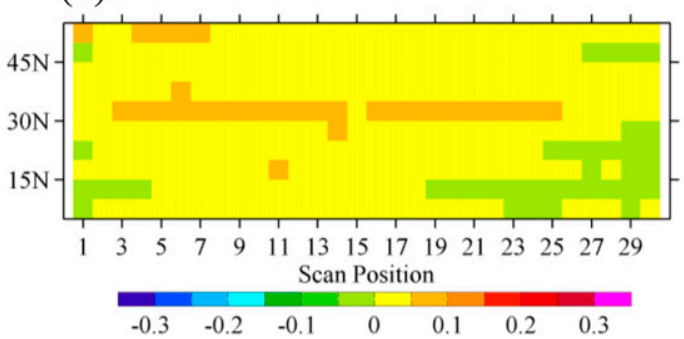

(c)

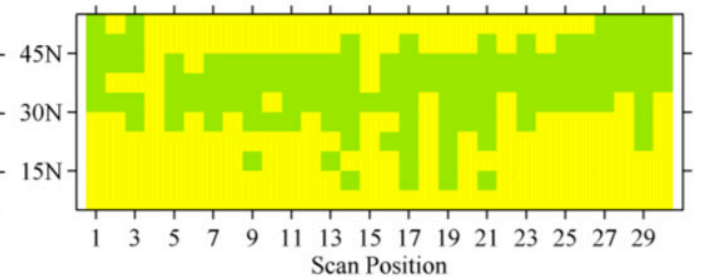

(d)

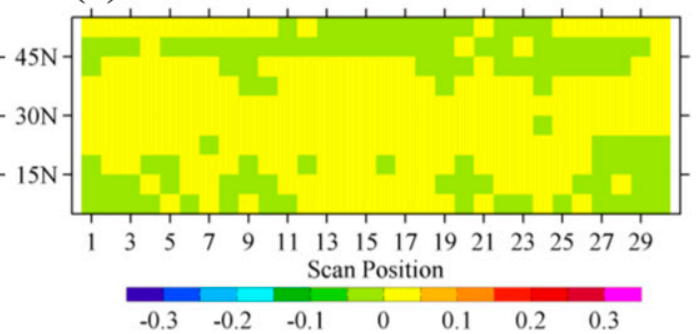

FIG. 12. $O-B$ brightness temperature biases after (a) the airmass BC and (b) the modified BC for channel 67 $(122 \mathrm{hPa})$ within $5^{\circ}$ latitudinal intervals and with respect to scan position ( $x$ axis) and latitude ( $y$ axis). $O-A$ brightness temperature biases after (c) the airmass BC and (d) the modified BC for LWIR channel 67 (122 hPa). 

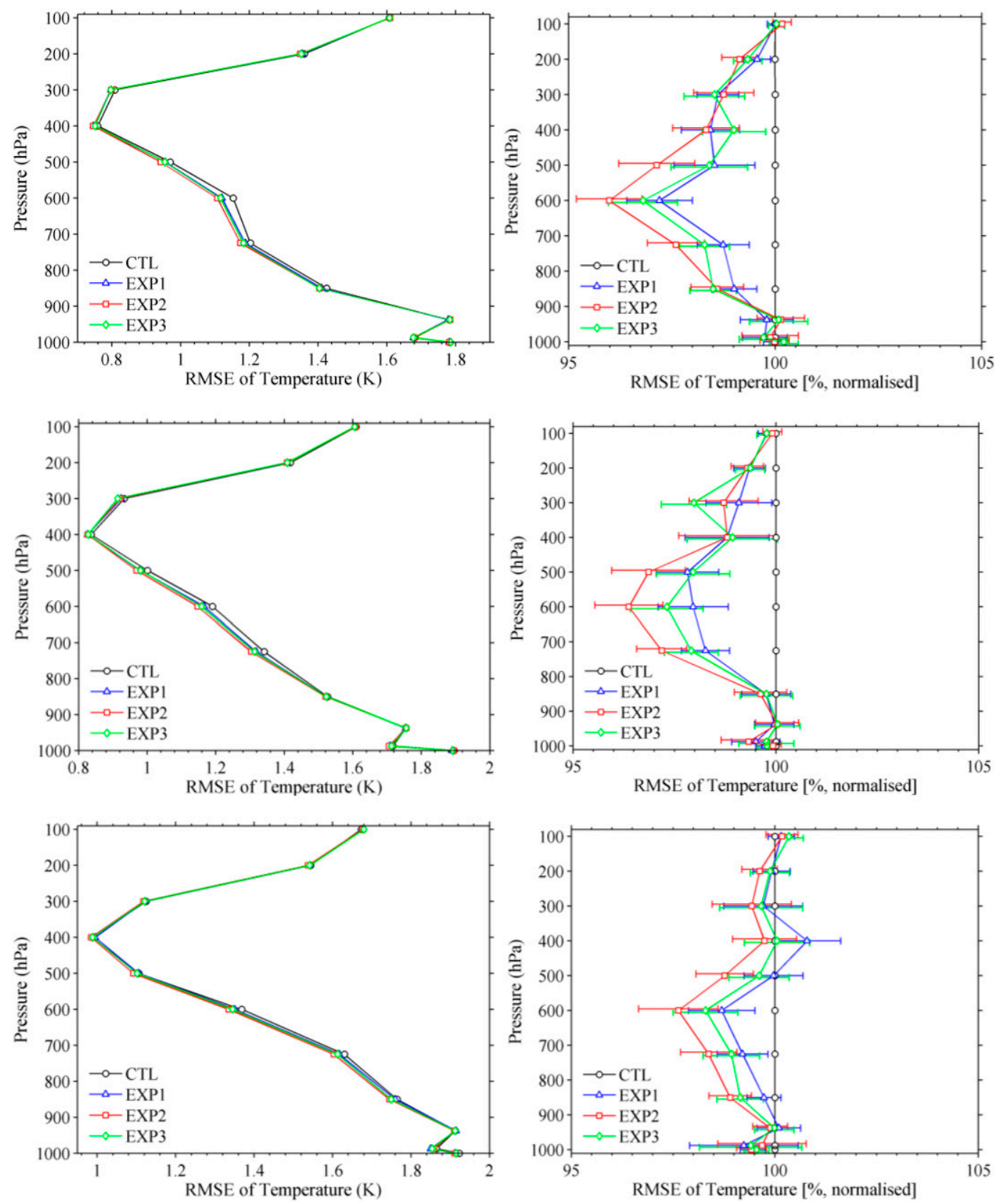

FIG. 13. Averaged vertical RMSE profiles of (left) temperature for the (top) 12-, (middle) 24-, and (bottom) 48-h forecast compared with conventional observations sampled from the 1-month assimilation experiments. (right) Vertical RMSE profiles of temperature normalized by the RMSE from the CTL experiment. Error bars give statistical significance intervals for differences from the CTL at the $95 \%$ level.

constrained by the fit to other observations in the VarBC, so the airmass $\mathrm{BC}$ scheme tends to minimize $O-A$ (Fig. 12c). As a result, the residual $O-B$ biases (Fig. 12a) after the airmass $\mathrm{BC}$ can be attributed to the bias between $A$ and $B$. On the contrary, the modified BC scheme will minimize $O-B$ (Fig. 12b). The difference between the VarBC (EXP1) and the running average
$O-B$ scheme (EXP2) probably attributes to the fact that the former minimized the $O-A$ mean, and the latter minimized the $O-B$ mean. To confirm this, a bias correction scheme is tested in a configuration where the bias is based on the running average of $O-A$ (EXP3; green curve in Fig. 11) rather than $O-B$. It is seen that the biases after the VarBC (EXP1) are close to those of 

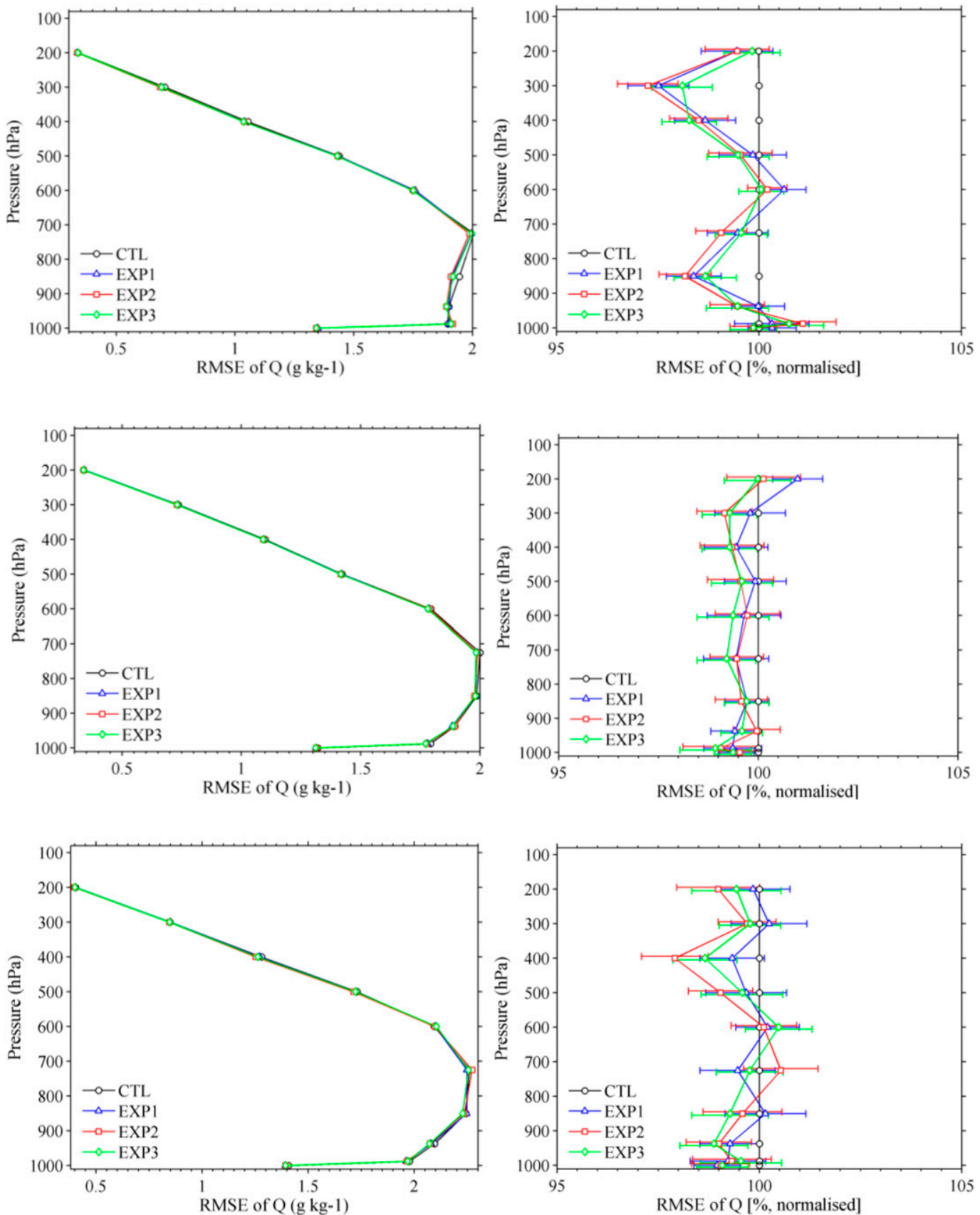

FIG. 14. As in Fig. 13, but for the RMSE of specific humidity.

EXP3 (Fig. 11), suggesting that the VarBC scheme does minimize the $O-A$ mean.

To evaluate the impact of CrIS radiance assimilation, forecasting results are verified against conventional observations (blue dots in Fig. 7). The root-mean-square errors (RMSEs) of the 12-, 24-, and 48-h forecasts are calculated for the four DA experiments, sampled from the 1-month period. Figure 13 displays the vertical profiles of RMSE for atmospheric temperature. The RMSE profiles from experiments EXP1, EXP2, and EXP3 normalized by the RMSE from the CTL experiment are also displayed. The temperature forecasts in the troposphere and the stratosphere are clearly improved by assimilating CrIS radiances for different forecasting times. It is not surprising that the assimilation of LWIR temperature-sensitive channels plays an 

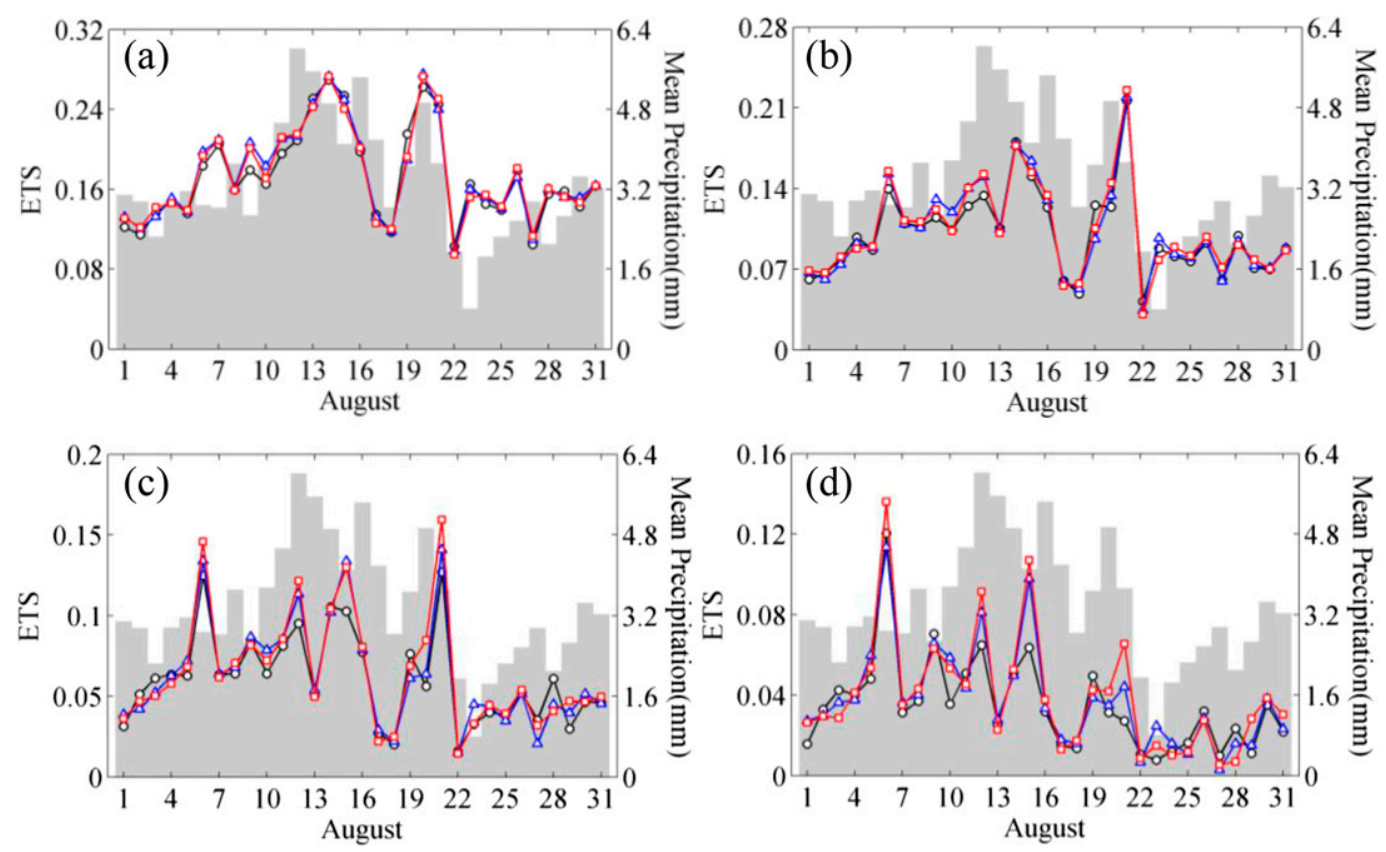

FIG. 15. Time series of the mean ETS for the CTL (black), EXP1 (blue), and EXP2 (red) experiments at the (a) 1-, (b) 5-, (c) 10-, and (d) 15-mm thresholds. The gray shading represents spatially averaged 24-h cumulative precipitation amounts on each day. Means are calculated as the average of eight ETSs covering a 24-h forecasting period.

important role in improving atmospheric temperature forecasts. Experiment EXP2 has smaller RMSEs than experiment EXP1, especially in the middle troposphere, suggesting that the use of the modified CrIS BC scheme has a positive impact on assimilation and the subsequent forecasts. The reduction in RMSE is $4 \%, 4 \%$, and $2.5 \%$ in the EXP2 experiment for the 12-, 24-, and 48-h forecasts, respectively, compared with the CTL experiment.

Figure 14 shows the vertical profiles of RMSE for specific humidity. In general, experiments EXP1, EXP2, and EXP3 show a neutral or slight improvement over the CTL experiment for each forecasting time. But the reduction of forecast error brought by CrIS data assimilation is seen during the entire 48 -h forecast period. The largest improvements are found around 300 and $850 \mathrm{hPa}$. Because some of the CrIS channels located in the LWIR band are also sensitive to water vapor (Fig. 1a), the assimilation of CrIS LWIR radiances is expected to improve the humidity fields. The EXP2simulated specific humidity fields agree slightly better with observations than those from EXP1 at all forecast times. By contrast, EXP1 RMSEs are comparable to CTL RMSEs.

Based on the forecasting RMSEs of atmospheric temperature and humidity, both EXP2 and EXP3 perform better than EXP1, suggesting the modified $\mathrm{BC}$ scheme works better than the airmass BC scheme.
EXP2 has noticeably smaller RMSEs of temperature forecasts than those of EXP3, especially in the midtroposphere. This comparison between EXP2 and EXP3 also suggests that minimizing $O-B$ performs better than minimizing $O-A$.

Figure 15 shows time series of the equitable threat score (ETS) of 3-h cumulative precipitation for the three DA experiments, together with the spatially averaged 24-h cumulative precipitation. The predicted precipitation are verified against U.S. gridded multisensor precipitation observations (Lin and Mitchell 2005) collected in eastern and central United States (black box area shown in Fig. 7a), where most of the August 2016 convective precipitation occurred. Mean 3-h ETSs calculated by averaging the first eight 3 -h cumulative windows of each forecast are plotted. For the 1- and 5-mm thresholds, ETSs from the EXP1 and EXP2 experiments are comparable to or slightly better than the CTL experiment ETSs during the whole month (Figs. 15a,b). However, for higher precipitation thresholds, noticeably higher ETSs are found in EXP2, especially on those days when heavy rain fell (Figs. 15c,d).

Overall, based on the verification of the 1-month-long forecasting results of atmospheric temperature, humidity, and precipitation, it appears that the modified BC scheme is preferable to the traditional airmass $\mathrm{BC}$ scheme for CrIS DA. 
(a)

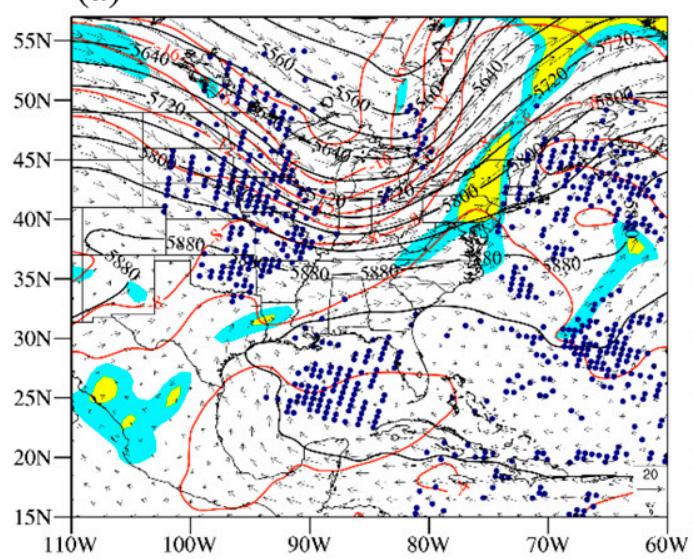

(c)

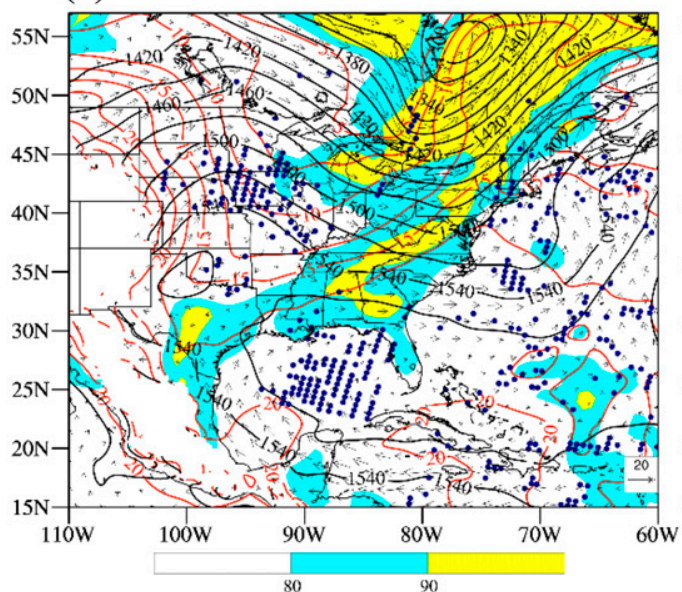

(b)

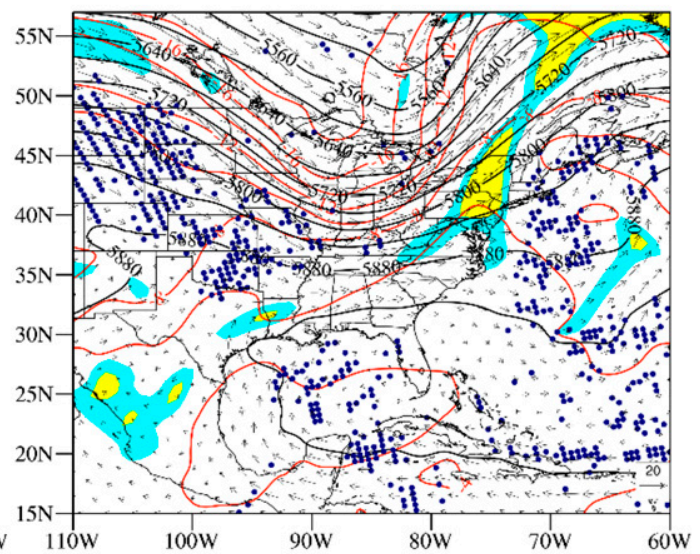

(d)

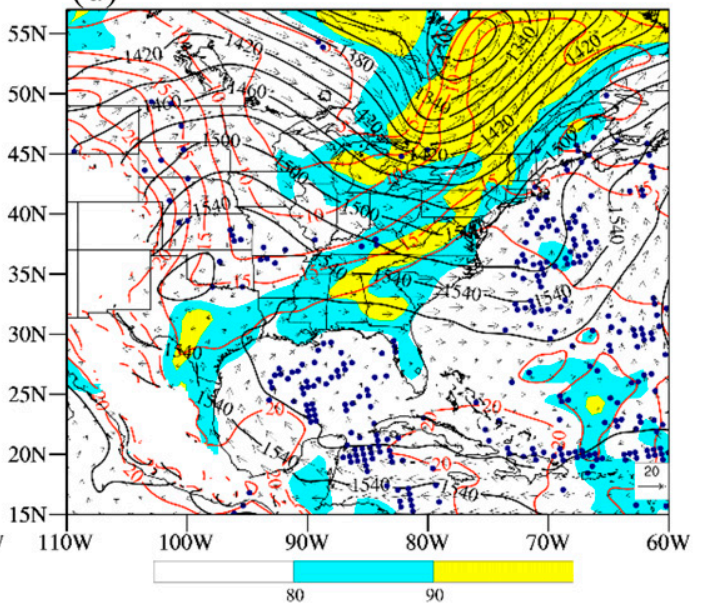

FIG. 16. Geopotential height (black contours), temperature (red contours), relative humidity (color shaded; unit: \%), and wind field (vector; unit: $\mathrm{m} \mathrm{s}^{-1}$ ) for $0.25^{\circ} \times 0.25^{\circ} \mathrm{NCEP}$ FNL analyses at (a),(c) 0600 and (b),(d) 1800 UTC 21 Aug at (a),(b) 500 and (c),(d) $850 \mathrm{hPa}$. CrIS data distributions near 500 (channel 101) and $850 \mathrm{hPa}$ (channel 151) are shown as blue dots.

\section{b. A convective precipitation case on 21 August 2016}

We also investigate the impact of CrIS DA on a convective precipitation case in northeastern United States that occurred on 21-22 August 2016. As illustrated in Fig. 7b, the CTL experiment and the two CrIS DA experiments (EXP1 and EXP2) for this single case are initialized by the GFS global analysis at 0000 UTC, and the forecasts are launched at 1800 UTC 21 August 2016 after the 18 -h cycled DA. It is reminded that the "modified BC scheme" only refers to EXP2.

For a brief synoptic overview, Fig. 16 displays the geopotential height, temperature, relative humidity, and wind fields of NCEP Final (FNL) analyses at 500 and $850 \mathrm{hPa}$ from 0600 to 1800 UTC 21 August 2016. At 0600 UTC, the 500-hPa North American trough was located in the middle of the United States, ahead of the 500-hPa temperature trough (Fig. 16a). Cold advection
(Fig. 16a) made the 500-hPa geopotential height trough develop further and move eastward at 1800 UTC 21 August (Fig. 16b). At $850 \mathrm{hPa}$, a low pressure system was found around $85^{\circ} \mathrm{W}$ at 0600 UTC 21 August (Fig. 16c). At 1800 UTC 21 August, the low pressure system was strengthened and moved eastward (Fig. 16d). The southwesterly flow to the south of the low pressure system was also strengthened, which transported an abundance of water vapor from the Gulf of Mexico to the eastern coastal area (Fig. 16d). Under the combined effects of a high-level trough and low-level low pressure, convective weather took place and brought heavy rain to the eastern coastal region.

Figure 17 shows the 3 -h cumulative precipitation predicted by the CTL, EXP1, and EXP2 experiments for $0-3,3-6,6-9$, and $9-12 \mathrm{~h}$, along with corresponding U.S. gridded multisensor precipitation observations. 
1800-2100 UTC
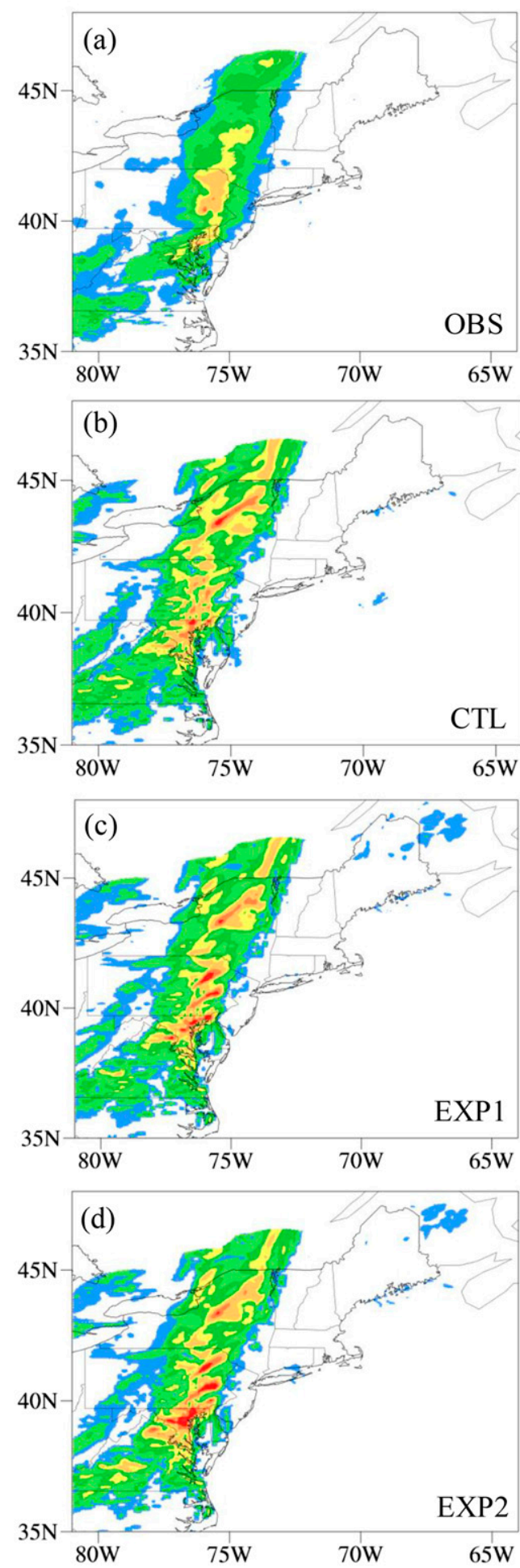

2100-0000 UTC
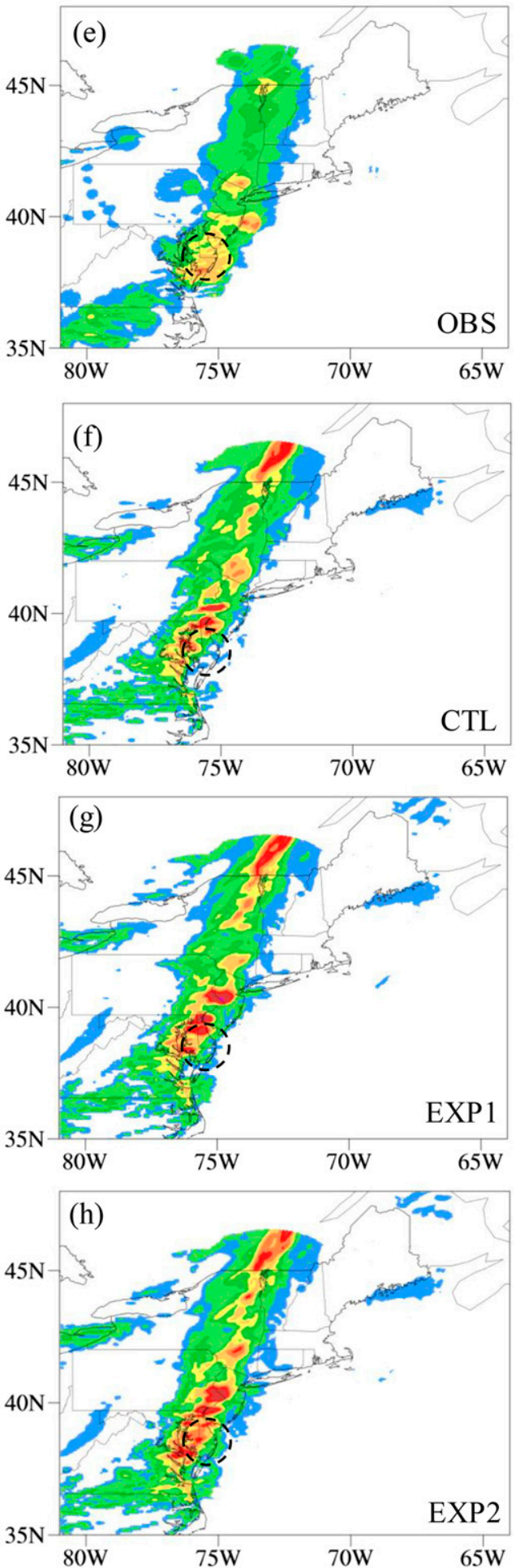

FIG. 17. Three-hour cumulative precipitation from 1800 UTC 21 Aug to 0600 UTC 22 Aug from U.S. gridded multisensor precipitation observations and the CTL, EXP1, and EXP2 experiments. 
0000-0300 UTC
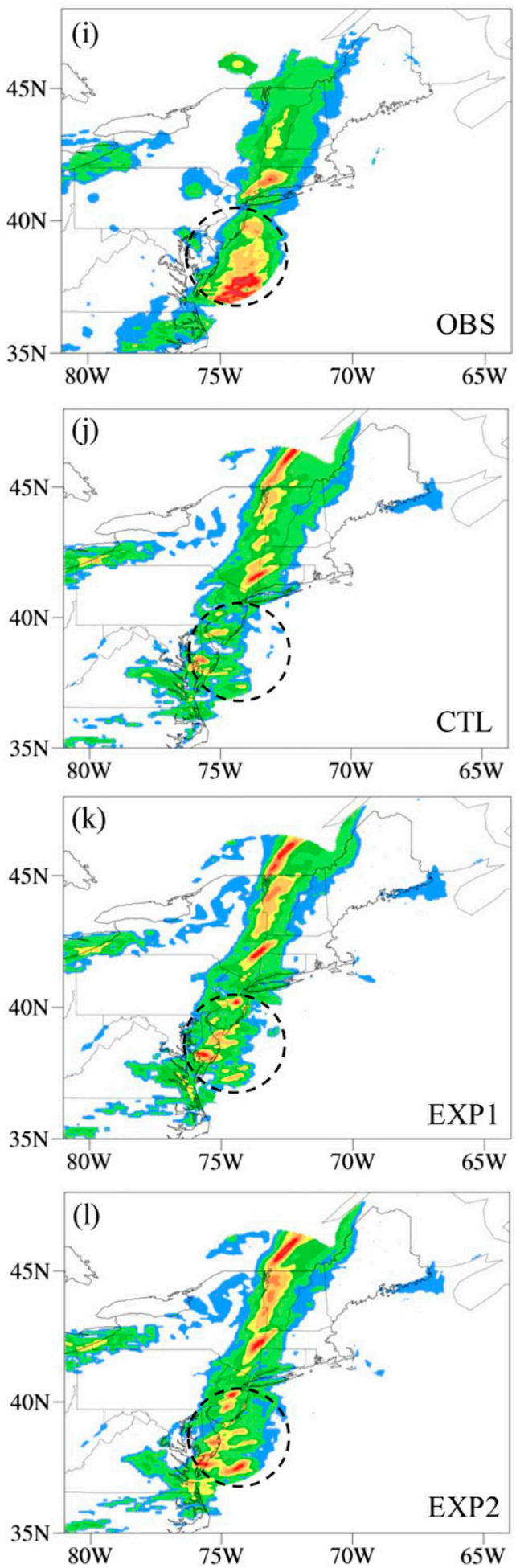

0300-0600 UTC

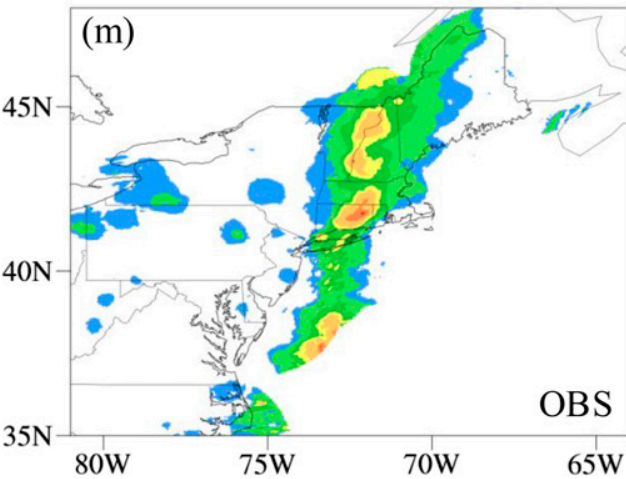

(n)
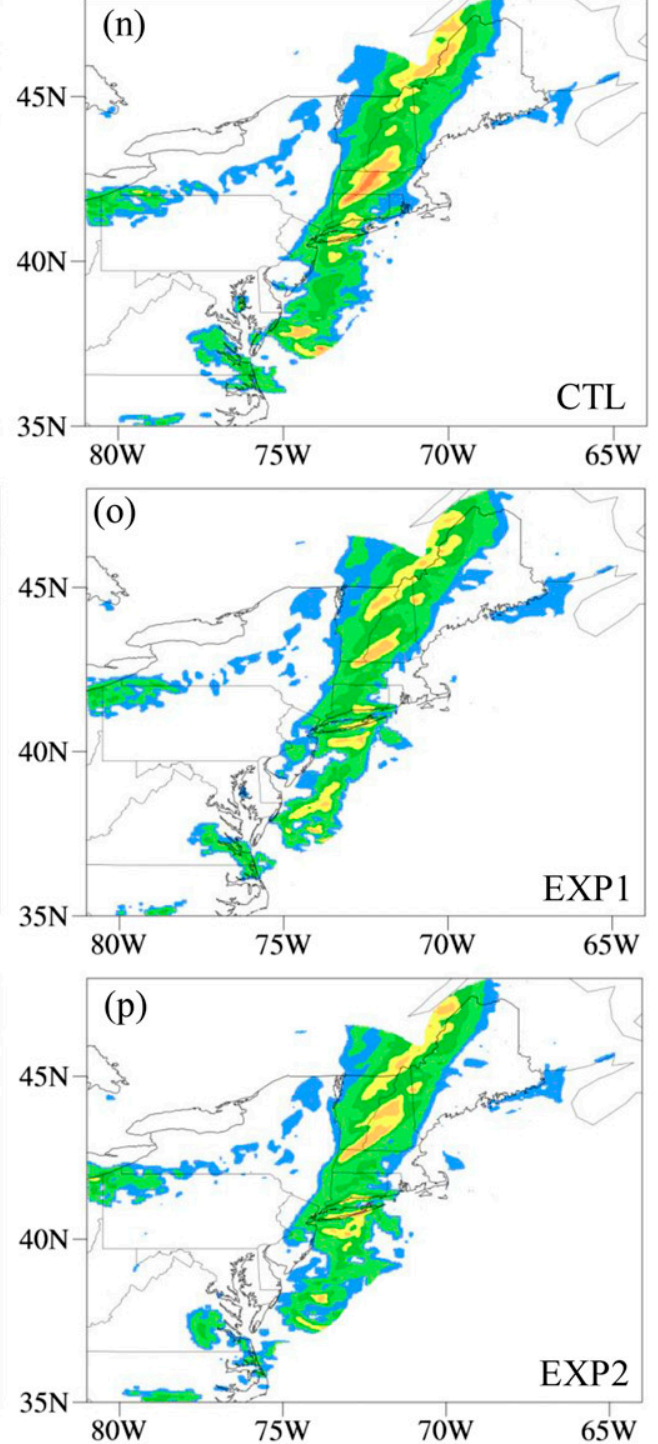

FIG. 17. (Continued) 
(a)

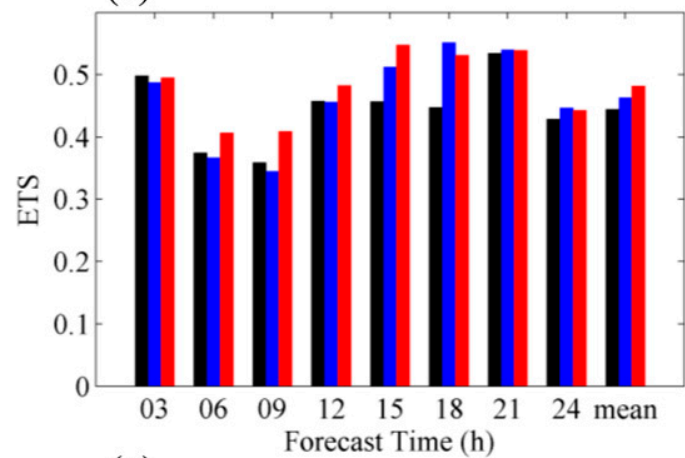

(c)

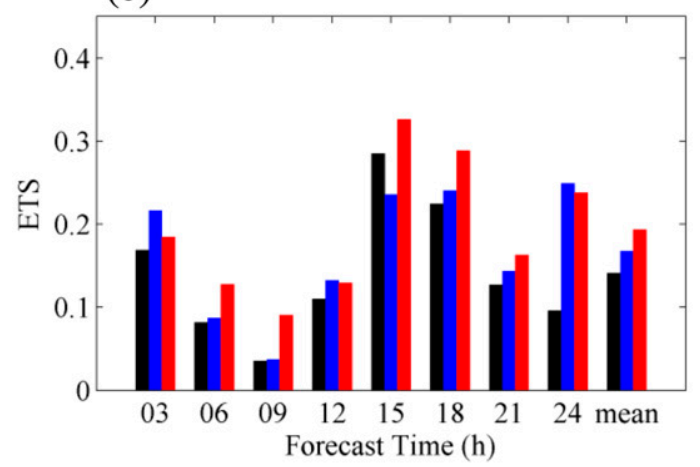

(b)

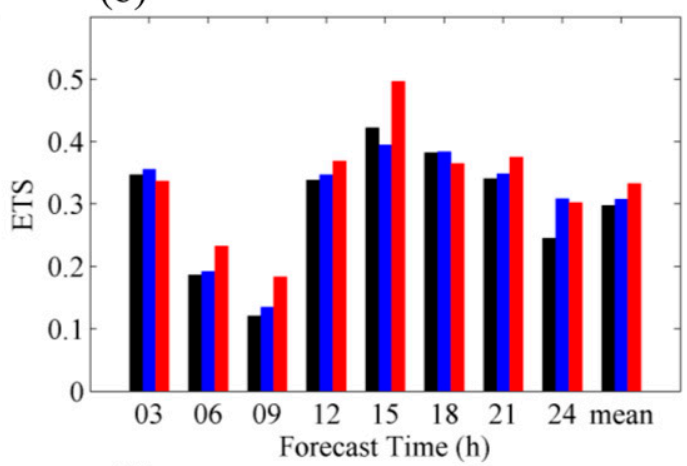

(d)

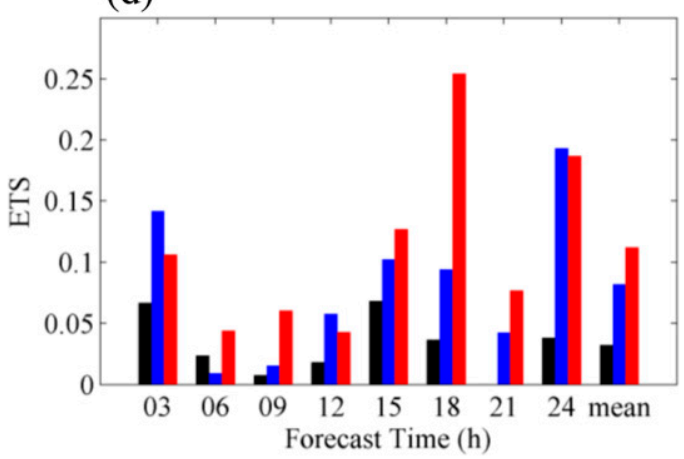

FIG. 18. ETS of 3-h cumulative precipitation for the CTL (black bars), EXP1 (blue bars), and EXP2 (red bars) experiments at the (a) 1-, (b) 5-, (c) 10-, and (d) 15-mm thresholds from 1800 UTC 21 Aug to 1800 UTC 22 Aug.

Generally, as the observed precipitation band moved eastward, the predicted rainfall location showed a noticeable western bias during the 3-6 and 6-9 forecasting hours in CTL (Figs. 17f,j) and EXP1 (Figs. 17g,k). On the contrary, the predicted rainfall bands in EXP2 (Figs. 17h,l) located more eastward than those in CTL and EXP1, which compared more favorably with observations (Figs. 17e,i). The precipitation forecasting performance is also supported by ETS. The ETSs of 3-h cumulative rainfall at the 1-, 5-, 10-, and 15-mm thresholds on the quantitative precipitation forecast (QPF) are shown in Fig. 18. Experiments EXP1 and EXP2 outperform experiment CTL for all thresholds and nearly all forecast times, suggesting the positive impact of CrIS radiance assimilation. The EXP2 experiment shows the largest improvement, especially for larger thresholds.

The causes for the improved precipitation forecast by CrIS DA are diagnosed. Focusing on the initial condition, Fig. 19 shows the differences in 500-hPa temperature between EXP1 and CTL at 0600 (first analysis) and 1800 UTC 21 August (final analysis) and the differences between the EXP2 and CTL experiments. In the first analysis, assimilating CrIS radiances adjusted the atmospheric temperatures in both the EXP1 (Fig. 19a) and EXP2 (Fig. 19b) experiments, which led to the eastward movement of the 500-hPa temperature trough. A deeper temperature trough was found in the EXP2 experiment (Fig. 19b), compared with the EXP1 experiment (Fig. 19a). Larger negative $O-B$ values after BC in EXP2 (Fig. 19d) are found than in EXP1 (Fig. 19c) near the location of the deeper temperature trough. The difference in temperature adjustment between EXP2 and EXP1 can be ascribed to the different BC schemes applied in CrIS DA. In the final analysis, the 500-hPa temperature trough seen in the EXP2 experiment is still located more to the east than in the CTL experiment (Fig. 19f). The adjustment of upper-level temperature fields played an important role in the subsequent movement and development of the high-level geopotential height trough and ridge. In comparison, the location of the 500-hPa temperature trough in the EXP1 experiment was not so obviously adjusted (Fig. 19e).

To explain why EXP2 better predicted the precipitation coverage than the other two experiments, Fig. 20 shows the differences in 500-hPa geopotential height between the EXP1 and CTL experiments and the differences between the EXP2 and CTL experiments at 0000 UTC 22 August 2016. After the 18-h cycled assimilation and 6-h forecast, the 500-hPa North American trough in the EXP2 experiment was located more to the 
(a)

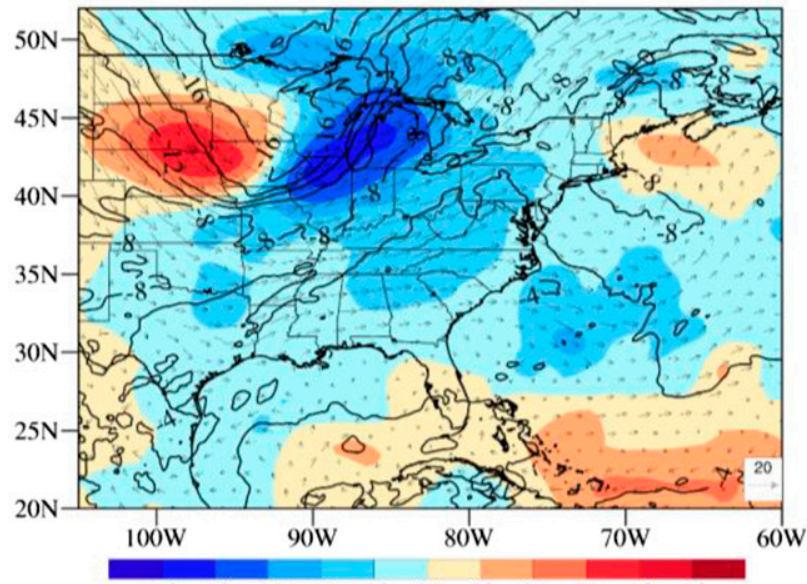

(c)

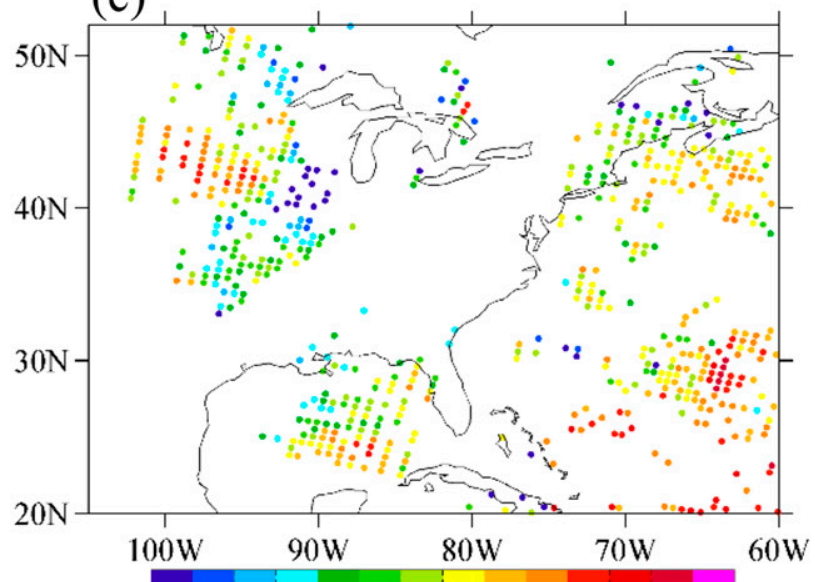

(e)

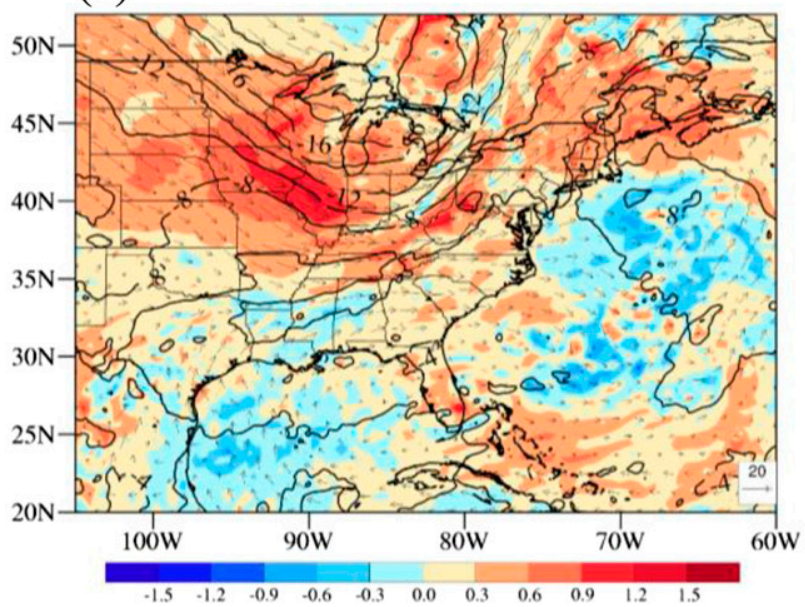

(b)

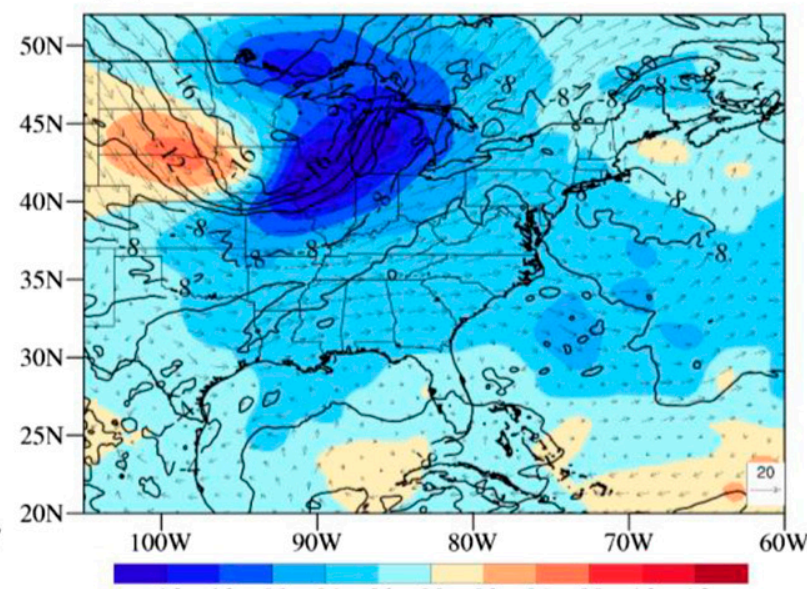

(d)

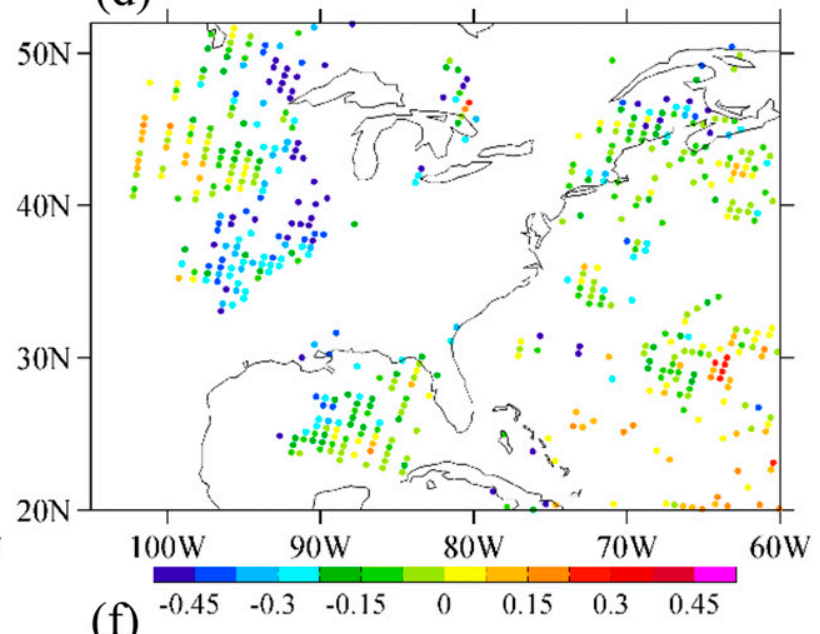

(f)

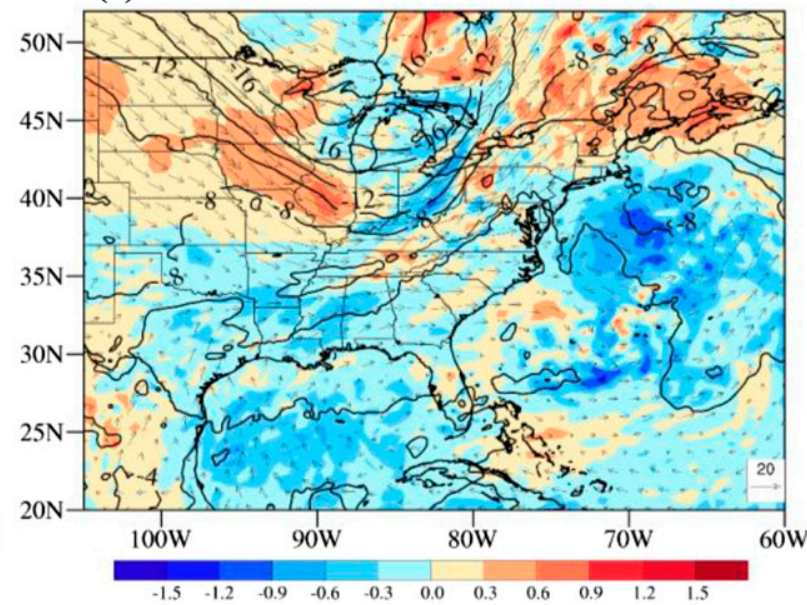

FIG. 19. Differences in 500-hPa analyzed temperature (color shaded) between (a) EXP1 and CTL (EXP1 minus CTL; solid lines) and between (b) EXP2 and CTL (EXP2 minus CTL; solid lines) at 0600 UTC 21 Aug. (c),(d) The $O-B$ biases of CrIS channel 101 (478 hPa) after airmass BC and the modified BC. (e),(f) As in (a),(b), but for 1800 UTC 21 Aug. 
(a)

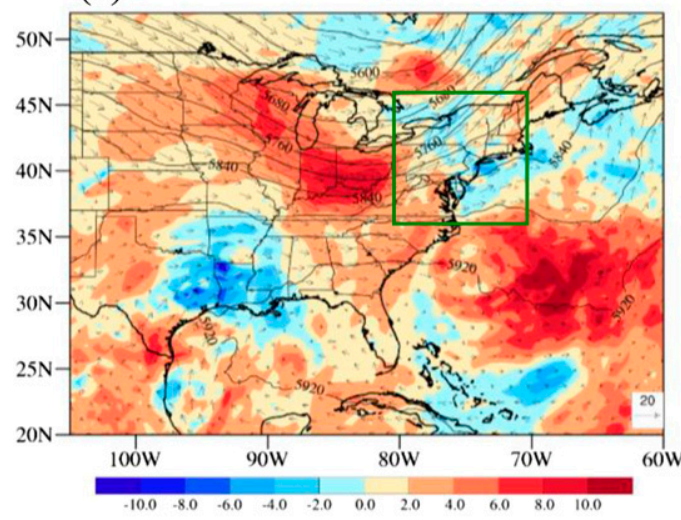

(b)

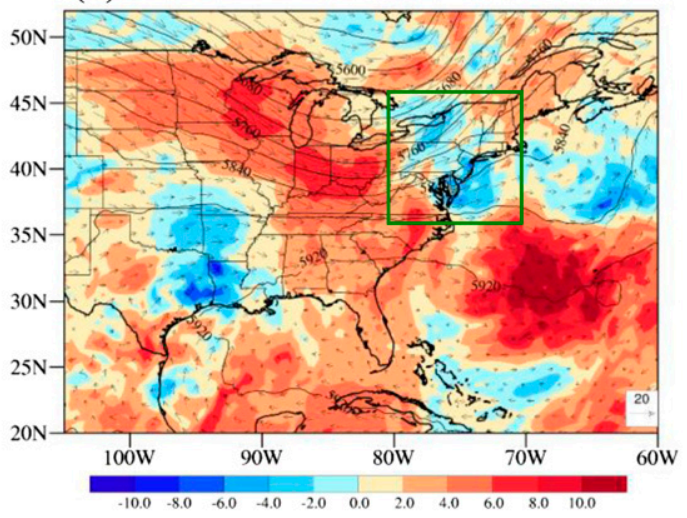

FIG. 20. Differences in 500-hPa geopotential height (color shaded) between (a) EXP1 and CTL (EXP1 minus CTL; solid lines) and between (b) EXP2 and CTL (EXP2 minus CTL; solid lines) at 0000 UTC 22 Aug (6-h forecasting time).

east than in the CTL experiment (Fig. 20b). In this case, convective precipitation occurred in the updraft region before the $500-\mathrm{hPa}$ geopotential height trough. The eastward adjustment of the upper-level trough resulted in the subsequent eastward shift in precipitation in the EXP2 experiment (Fig. 171), compared with the CTL experiment (Fig. 17j). As a result, the precipitation distributions in the EXP2 experiment (Figs. 171,p) agree well with observations (Figs. 17i,m) from 0000 to 0600 UTC 22 August 2016. Compared with the EXP2 experiment (Fig. 20b), experiment EXP1 (Fig. 20a) showed less adjustment of the 500-hPa North American trough, so the predicted rainfall coverage in the EXP1 experiment (Fig. 17k) was similar to that in the CTL experiment.

Figure 21 shows the vertical difference in pseudoequivalent potential temperature $\left(\partial \theta_{\mathrm{se}} / \partial p\right)$, a measure of the atmospheric thermodynamic instability, at 0000 UTC 22 August 2016 for experiments CTL, EXP1, and EXP2. For convective weather, lower energy at a lower level of the atmosphere $\left(\theta_{\mathrm{se}}^{850}\right)$ overlapped by higher energy at a higher level $\left(\theta_{\mathrm{se}}^{500}\right)$ is beneficial for atmospheric instability. In experiment EXP2 (Fig. 21c), thermal instability $\left(\theta_{\mathrm{se}}^{500}-\theta_{\mathrm{se}}^{850}\right)$ in the offshore areas of Maryland and Delaware was greater than that in the CTL (Fig. 21a) and EXP1 (Fig. 21b) experiments. Therefore, more available potential energy in the EXP2 experiment resulted in the increased likelihood of convective precipitation in the offshore areas at the subsequent forecasting times.

Based on the analysis of the convective precipitation case, the assimilation of CrIS radiances plays an important role in adjusting atmospheric temperature fields. After application of the modified BC scheme, the analyzed fields represent a preferable environmental configuration of geopotential troughs/ridges and thermal instability for coastal precipitation.

\section{Verification of model bias against GPS RO data}

The modified $\mathrm{BC}$ scheme produces smaller $O-B$ biases than the traditional airmass BC scheme for CrIS DA in the regional application. However, as discussed by Eyre (1992), a satellite radiance BC approach designed to minimize $O-B$ may correct bias relative to NWP model. If the model background bias is obvious, it may lead to a reinforcement of the model bias during the cycled DA procedure. Therefore, it is crucial to check if the model background bias is present and whether it shows a drift tendency during the assimilation cycles. In other words, a verification result of no obvious model background bias from experiment EXP2 will ensure the robustness of the modified BC scheme applied in the regional model.

As investigated in many previous studies (Rocken et al. 1997; Lin et al. 2010; Yang and Zou 2012), the global positioning system (GPS) radio occultation (RO) data have high accuracy, high vertical resolution, and high stability. Profiles of GPS refractivity can be used to retrieve atmospheric profiles of temperature and water vapor using a one-dimensional variational (1DVar) DA algorithm (Healy and Eyre 2000; Palmer et al. 2000). GPS RO sounding profiles have been widely used as input of RTMs to assess the accuracy of satellite brightness temperatures (Schrøder et al. 2003; Ho et al. 2009; Zou et al. 2014; Chen and Zou 2014). This section aims at assessing the model background bias in the CrIS brightness temperature space using collocated GPS RO sounding profile data. 
(a)

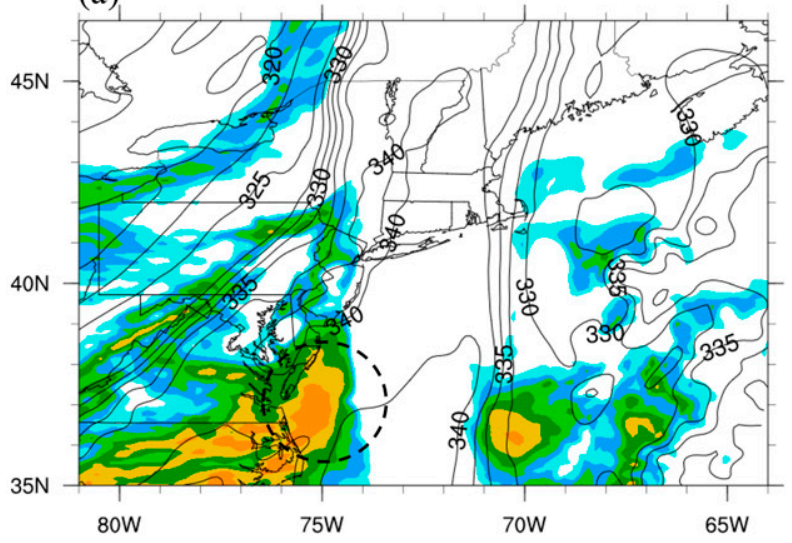

(b)
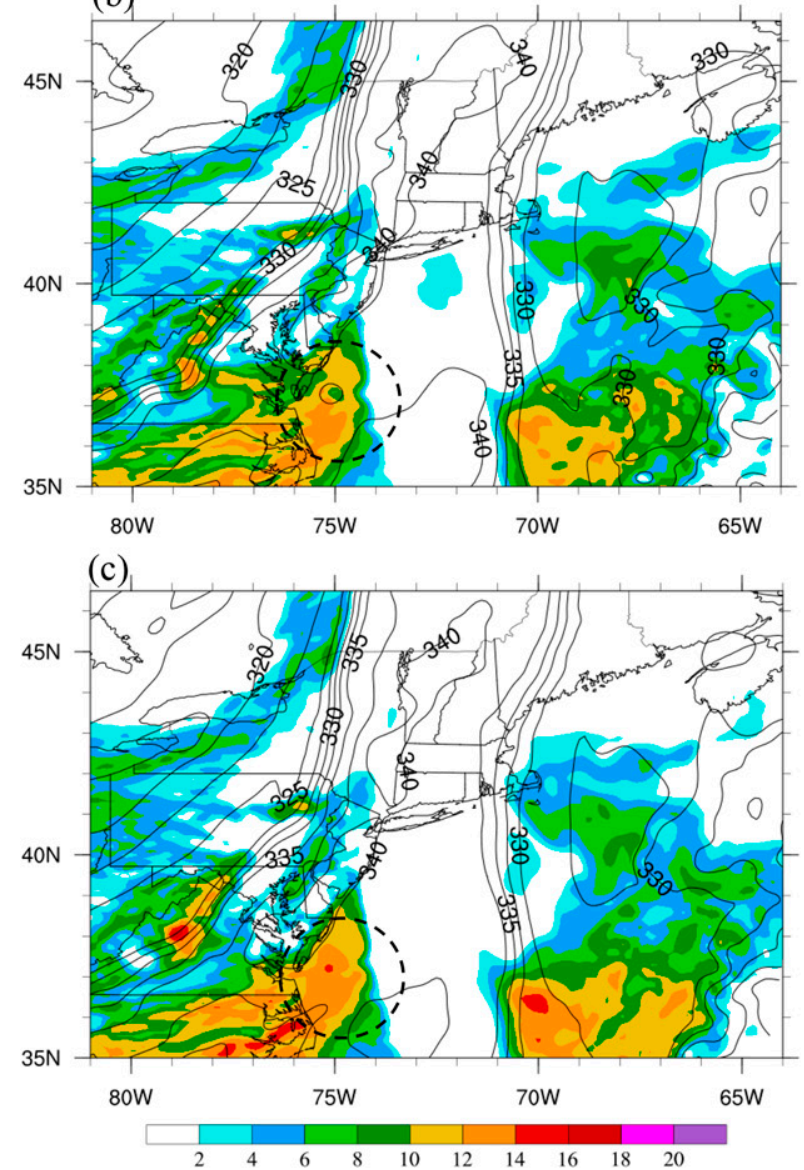

FIG. 21. Pseudoequivalent temperature at $500 \mathrm{hPa}$ (contours; units: $\mathrm{K}$ ) and the difference in pseudoequivalent temperature between 850 and $500 \mathrm{hPa}\left(\theta_{\mathrm{se}}^{500}-\theta_{\mathrm{se}}^{850}\right.$; color shaded; units: $\left.\mathrm{K}\right)$ for the (a) CTL, (b) EXP1, and (c) EXP2 experiments at 0000 UTC 22 Aug.

To obtain a sufficiently large sample of GPS RO data collocated with model data, GPS ROs from the following five missions are used: the Constellation Observing System for Meteorology, Ionosphere, and Climate
(COSMIC) mission (Anthes et al. 2008); the Gravity Recovery and Climate Experiment (GRACE) mission (Wickert et al. 2005); the Global Navigation Satellite System Receiver for Atmospheric Soundings (GRASs) on board MetOp-A and MetOp-B; and the German TerraSAR-X mission. Collocation criteria between model background profiles and GPS RO profiles are defined as a time difference of fewer than $3 \mathrm{~h}$ and a horizontal spatial separation of fewer than $20 \mathrm{~km}$. The CRTM is employed to simulate CrIS brightness temperatures using GPS RO profiles as input $\left(T_{b}^{\mathrm{RO}}\right)$ and using model background profiles as input $\left(T_{b}^{B}\right)$. Then, the mean difference in simulated brightness temperature $\left(\overline{T_{b}^{B}-T_{b}^{\mathrm{RO}}}\right)$ is used to represent the model background bias. Since GPS RO profiles are most accurate within the height range between 5 and $30 \mathrm{~km}$ (Kursinski et al. 1996; Anthes et al. 2008; Kishore et al. 2009), only CrIS channels with WF peaks at upper and midlevels of the atmosphere are selected for brightness temperature simulations. For surface state variables that are not provided by GPS RO profiles, the WRF Model surface wind and surface temperature are used as CRTM input for the GPS-simulated brightness temperature $T_{b}^{\mathrm{RO}}$.

Figure 22a shows an example of the distribution of model background profiles collocated with GPS RO profiles on 21 August 2016. Collocated GPS RO locations at three different DA cycles (i.e., 0600, 1200, and 1800 UTC) are indicated by three different colors. Figures $22 \mathrm{~b}-\mathrm{d}$ display the simulated brightness tem-

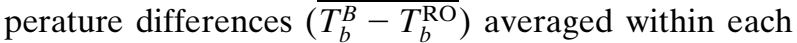
DA cycle of experiment EXP2 for channel $67(122 \mathrm{hPa})$, channel $87(287 \mathrm{hPa})$, and channel $104(521 \mathrm{hPa})$, respectively, during the 1 -month experiment. Because the cycled DA is performed every day at 0600 , 1200, and 1800 UTC (Fig. 7b), we calculate the model background bias at these three times every day. For the stratospheric channel 67 (Fig. 22b), the monthly mean background bias $\left(\overline{T_{b}^{B}-T_{b}^{\mathrm{RO}}}\right)$ is $0.07,0.04$, and $0.06 \mathrm{~K}$ at 0600,1200 , and $1800 \mathrm{UTC}$, respectively. The background bias varies within an acceptable range during the cycled DA. For the upper-level tropospheric channel 87 (Fig. 22c), the monthly mean background bias $\left(\overline{T_{b}^{B}-T_{b}^{\mathrm{RO}}}\right)$ is $-0.03,-0.04$, and $-0.01 \mathrm{~K}$ at 0600 , 1200 , and 1800 UTC, respectively. For the midlevel tropospheric channel 104 (Fig. 22d), the monthly mean background bias $\left(\overline{T_{b}^{B}-T_{b}^{\mathrm{RO}}}\right)$ is $-0.07,-0.06$, and $-0.05 \mathrm{~K}$ at 0600,1200 , and 1800 UTC, respectively.

Based on the above verification results against GPS RO profile data, it is demonstrated that the model background biases are negligibly small and do not vary with time during the DA cycle. The modified BC scheme is robust for regional applications. 
(a)
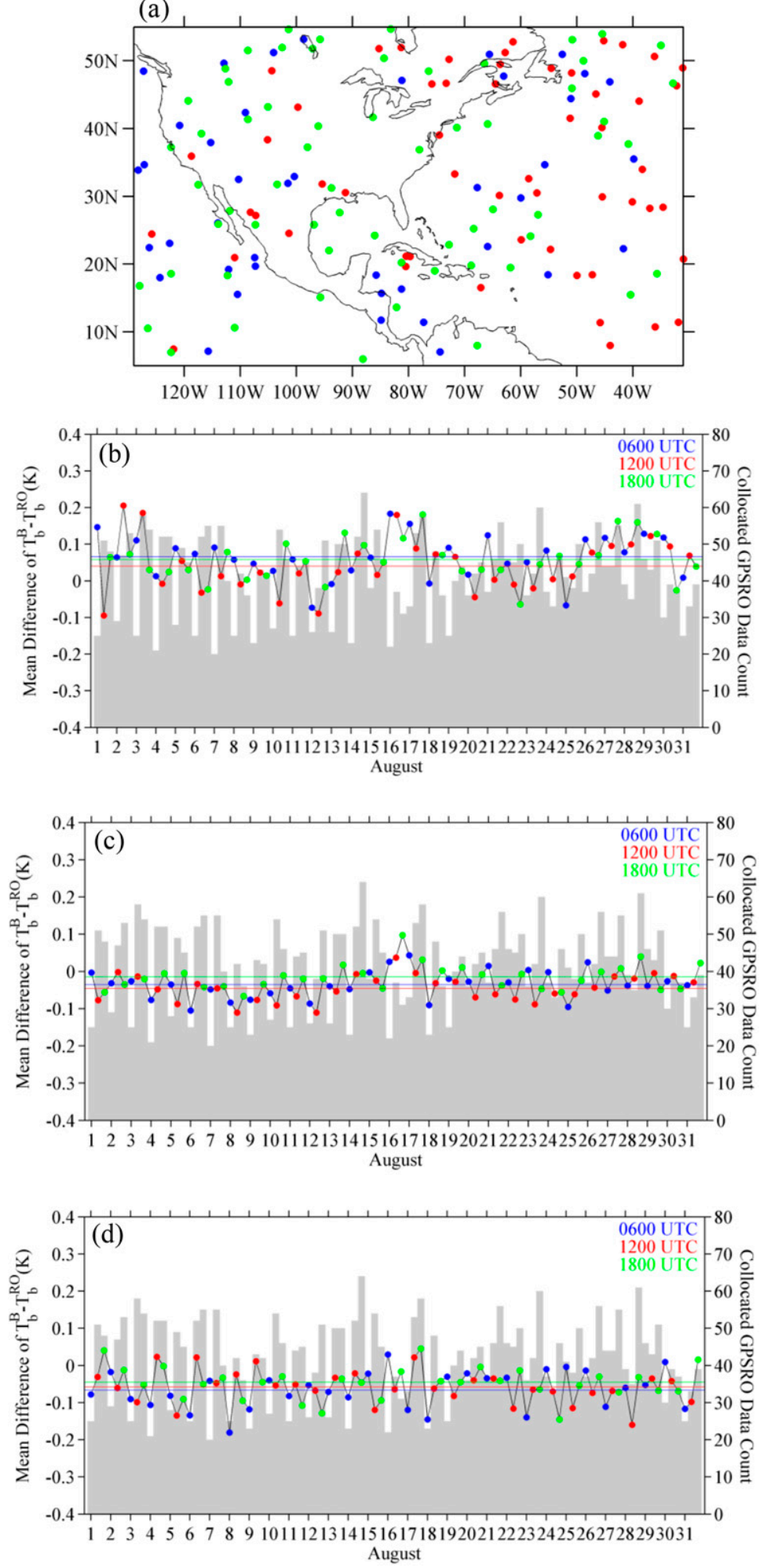

FIG. 22. (a) The distribution of GPS RO profiles collocated with model background profiles on $21 \mathrm{Aug} 2016$. The simulated brightness temperature difference $\left(\overline{T_{b}^{B}-T_{b}^{\mathrm{RO}}}\right)$ averaged on each assimilation time during the 1-month experiment for (b) channel $67(122 \mathrm{hPa})$, (c) channel $87(287 \mathrm{hPa})$, and (d) channel 104 


\section{Summary and conclusions}

This study focuses on the bias correction (BC) scheme for CrIS radiance data assimilation (DA). Based on a correlation analysis, the ability of the airmass BC predictors of the NCEP GSI system in modeling the observation-minus-background $(O-B)$ biases of CrIS channels is diagnosed. Statistics from a 2-week clear-sky data sample reveal that the correlations between CrIS $O-B$ departures and the lapse rate airmass predictors employed by the GSI system are very weak. This suggests that the particular choice of airmass predictors used in the traditional GSI BC scheme is inadequate for CrIS radiance data assimilation.

A simpler modified BC scheme is thus proposed and incorporated into the NCEP GSI system for CrIS DA, calculated using the equally weighted moving average of $O-B$ departures from data of the previous 2 weeks. The idea behind this proposed $\mathrm{BC}$ scheme is to use recent $O-B$ statistics to perform a BC with respect to both scan position and latitudinal band. The impacts of the modified BC scheme on CrIS radiance DA and regional NWP are tested and compared with the impact of the traditional airmass $\mathrm{BC}$ scheme.

Four cycled DA assimilation experiments are carried out for a 1-month period to verify the effectiveness of the two BC schemes. The benchmark control experiment, CTL, only assimilates conventional data and AMSU-A microwave radiance data. Experiments EXP1 and EXP2 additionally assimilate CrIS radiances using the airmass $\mathrm{BC}$ scheme and the modified $\mathrm{BC}$ scheme, respectively. The modified $\mathrm{BC}$ scheme better corrects scan-dependent and latitude-dependent biases for CrIS LWIR stratospheric channels, tropospheric channels, and surface channels, while residual biases are still found in some of the CrIS channels when the airmass BC scheme is applied. Experiment EXP2 with the modified $\mathrm{BC}$ scheme produces a smaller rootmean-square error for predicted atmospheric temperature and specific humidity in short-range forecasts than experiments CTL and EXP1. The greatest improvement is found in the temperature fields of the midtroposphere. Experiment EXP3 is similar to EXP2, except for using observation-minus-analysis $(O-A)$ data samples in the previous 2 weeks for bias estimates.
A comparison among EXP1, EXP2, and EXP3 confirms that the improved forecasting results of EXP2 are also benefited from targeting bias correction on $O-B$, rather than $O-A$. Predicted precipitation from the DA experiments is verified against multisensor rainfall observations. For high-precipitation thresholds, noticeably higher equivalent threat scores are found in the EXP2 experiment, especially on those days with heavy rain.

A convective precipitation case that occurred along the northeastern coast of the United States on 2122 August 2016 is also investigated to examine the impact of the modified BC scheme on CrIS assimilation and the subsequent forecast. Among the three DA experiments, the EXP2 experiment compares favorably with multisensor 3-hourly rainfall observations. With the modified $\mathrm{BC}$ scheme, the temperature field was reasonably adjusted after CrIS DA in experiment EXP2, leading to the further evolution of the geopotential height trough and ridge. Thus, the better prediction of the precipitation coverage in the EXP2 experiment can be ascribed to the better prediction of environmental fields.

This paper examines the impact of incorporating a modified BC scheme into CrIS radiance DA and demonstrates its usefulness for NWP. For the use of CrIS data in regional models, the modified $\mathrm{BC}$ scheme has been shown to perform better than the airmass $\mathrm{BC}$ scheme. In other words, under the current configuration of the DA cycling strategy of this study for regional applications, the modified BC scheme that corrects the relative bias between satellite observations and the model background seems to have some merit for CrIS data assimilation. Although inadequate for the case study in this research, the variational airmass BC scheme within the current GSI system may be further improved by finding better predictors. Efforts will be made to explore alternative bias predictors to improve variational airmass BC scheme for CrIS data assimilation in our future study.

Furthermore, since the JPSS-1 satellite was successfully launched on 18 November 2017, a full spectral resolution product with a uniform channel spacing of $0.625 \mathrm{~cm}^{-1}$ is available for CrIS. The potential value of

$(521 \mathrm{hPa})$. The assimilation times of 0600,1200 , and 1800 UTC are indicated by blue, red, and green, respectively. The solid blue, red, and green lines represent the mean simulated brightness temperature difference $\left(\overline{T_{b}^{B}-T_{b}^{\mathrm{RO}}}\right)$ averaged by all the collocated data samples during the 1-month experiment at 0600, 1200, and 1800 UTC, respectively. Collocated GPS RO data counts at each assimilation time are indicated in gray shading. 
assimilating full-spectrum CrIS radiances should also be further explored in the future.

Acknowledgments. This research work was supported by the National Key R\&D Program of China (2017YFC1501805, 2017YFC1502104), the National Natural Science Foundation of China (Grants 41805076, 41475042, 41575036), the NOAA JPSS Proving Ground and Risk Reduction (PGRR) Program (NA14NES4320003), the Jiangsu Meteorological Bureau Key Research Fund Project (KZ201805), the Jiangsu Province Science and Technology Support Program (BE2015731), and the Social Common Wealth Research Program (GYHY201506006). We also thank the editor and four anonymous reviewers for their valuable and constructive suggestions that significantly improved the science presentation of this manuscript.

\section{REFERENCES}

Anthes, R. A., and Coauthors, 2008: The COSMIC/FORMOSAT3 mission: Early results. Bull. Amer. Meteor. Soc., 89, 313-334, https://doi.org/10.1175/BAMS-89-3-313.

Auligné, T., and A. P. McNally, 2007: Interaction between bias correction and quality control. Quart. J. Roy. Meteor. Soc., 133, 643-653, https://doi.org/10.1002/qj.57.

,-- , and D. P. Dee, 2007: Adaptive bias correction for satellite data in a numerical weather prediction system. Quart. J. Roy. Meteor. Soc., 133, 631-642, https://doi.org/10.1002/qj.56.

Aumann, H. H., and Coauthors, 2003: AIRS/AMSU/HSB on the Aqua mission: Design, science objectives, data products, and processing systems. IEEE Trans. Geosci. Remote Sens., 41, 253-264, https://doi.org/10.1109/ TGRS.2002.808356.

Chander, G., T. J. Hewison, N. Fox, X. Wu, X. Xiong, and W. J. Blackwell, 2013: Overview of intercalibration of satellite instruments. IEEE Trans. Geosci. Remote Sens., 51, 1056-1080, https://doi.org/10.1109/TGRS.2012.2228654.

Chen, F., and J. Dudhia, 2001: Coupling an advanced land surfacehydrology model with the Penn State-NCAR MM5 modeling system. Part I: Model implementation and sensitivity. Mon. Wea. Rev., 129, 569-585, https://doi.org/10.1175/1520-0493(2001) 129<0569:CAALSH > 2.0.CO;2.

Chen, X., and X. Zou, 2014: Postlaunch calibration and bias characterization of AMSU-A upper air sounding channels using GPS RO data. J. Geophys. Res. Atmos., 119, 3924-3941, https://doi.org/10.1002/2013JD021037.

Collard, A., J. Derber, and R. Treadon, 2012: Toward assimilation of CrIS and ATMS in the NCEP Global Model. 18th Int. TOVS Study Conf., Toulouse, France, TOVS, 1.21.

Dee, D. P., 2004: Variational bias correction of radiance data in the ECMWF system. ECMWF Workshop on Assimilation of High Spectral Resolution Sounders in NWP, Reading, United Kingdom, ECMWF, 16 pp., https://www.ecmwf.int/sites/default/ files/elibrary/2004/8930-variational-bias-correction-radiance-dataecmwf-system.pdf.

, 2005: Bias and data assimilation. Quart. J. Roy. Meteor. Soc., 131, 3323-3343, https://doi.org/10.1256/qj.05.137.

Derber, J. C., and W.-S. Wu, 1998: The use of TOVS cloud-cleared radiances in the NCEP SSI analysis system. Mon. Wea. Rev.,
126, 2287-2299, https://doi.org/10.1175/1520-0493(1998)126<2287: TUOTCC $>2.0 . \mathrm{CO} ; 2$.

Dudhia, J., 1989: Numerical study of convection observed during the Winter Monsoon Experiment using a mesoscale two-dimensional model. J. Atmos. Sci., 46, 3077-3107, https://doi.org/10.1175/ 1520-0469(1989)046<3077:NSOCOD>2.0.CO;2.

Engelen, R. J., and P. Bauer, 2014: The use of variable $\mathrm{CO}_{2}$ in the data assimilation of AIRS and IASI radiances. Quart. J. Roy. Meteor. Soc., 140, 958-965, https://doi.org/10.1002/qj.919.

Eresmaa, R., J. Letertre-Danczak, C. Lupu, N. Bormann, and T. McNally, 2017: The assimilation of Cross-track Infrared Sounder radiances at ECMWF. Quart. J. Roy. Meteor. Soc., 143, 3177-3188, https://doi.org/10.1002/qj.3171.

Eyre, J. R., 1992: A bias correction scheme for simulated TOVS brightness temperatures. ECMWF Tech. Memo. 186, 34 pp., https:/www.ecmwf.int/sites/default/files/elibrary/1992/9330-biascorrection-scheme-simulated-tovs-brightness-temperatures.pdf. , and W. P. Menzel, 1989: Retrieval of cloud parameters from satellite sounder data: A simulation study. J. Appl. Meteor., 28, 267-275, https://doi.org/10.1175/1520-0450(1989)028<0267: ROCPFS $>2.0 . \mathrm{CO} ; 2$.

Gambacorta, A., and C. D. Barnet, 2013: Methodology and information content of the NOAA NESDIS operational channel selection for the Cross-track Infrared Sounder (CrIS). IEEE Trans. Geosci. Remote Sens., 51, 3207-3216, https:// doi.org/10.1109/TGRS.2012.2220369.

Goldberg, M., and Coauthors, 2011: The Global Space-based InterCalibration System. Bull. Amer. Meteor. Soc., 92, 467-475, https://doi.org/10.1175/2010BAMS2967.1.

Han, Y., F. Weng, Q. Liu, and P. van Delst, 2007: A fast radiative transfer model for SSMIS upper atmosphere sounding channels. J. Geophys. Res., 112, D11121, https://doi.org/10.1029/ 2006JD008208.

— data record algorithm, calibration and validation activities, and record data quality. J. Geophys. Res. Atmos., 118, 12734 12 748, https://doi.org/10.1002/2013JD020344.

Harris, B. A., and G. Kelly, 2001: A satellite radiance-bias correction scheme for data assimilation. Quart. J. Roy. Meteor. Soc., 127, 1453-1468, https://doi.org/10.1002/qj.49712757418.

Healy, S., and J. Eyre, 2000: Retrieving temperature, water vapor and surface pressure information from refractivity-index profiles derived by radio occultation: A simulation study. Quart. J. Roy. Meteor. Soc., 126, 1661-1683, https://doi.org/ 10.1256/smsqj.56606.

Ho, S.-P., M. Goldberg, Y.-H. Kuo, C.-Z. Zou, and W. Schreiner, 2009: Calibration of temperature in the lower stratosphere from microwave measurements using COSMIC radio occultation: Preliminary results. Terr. Atmos. Ocean. Sci., 20, 87 100, https://doi.org/10.3319/TAO.2007.12.06.01(F3C).

Hong, S.-Y., and J.-O. J. Lim, 2006: The WRF Single-Moment 6-Class Microphysics Scheme (WSM6). J. Korean Meteor. Soc., 42, 129-151.

Kain, J. S., 2004: The Kain-Fritsch convective parameterization: An update. J. Appl. Meteor., 43, 170-181, https://doi.org/ 10.1175/1520-0450(2004)043<0170:TKCPAU>2.0.CO;2.

—_, and J. M. Fritsch, 1990: A one-dimensional entraining/ detraining plume model and its application in convective parameterization. J. Atmos. Sci., 47, 2784-2802, https:// doi.org/10.1175/1520-0469(1990)047<2784:AODEPM> 2.0.CO;2.

Kelly, G. A., and J. F. Flobert, 1988: Radiance tuning. Proc. Fourth Int. TOVS Conf., Igls, Austria, TOVS, 99-117. 
Kishore, P., S. P. Namboothiri, J. H. Jiang, V. Sivakumar, and K. Igarashi, 2009: Global temperature estimates in the troposphere and stratosphere: A validation study of COSMIC/ FORMOSAT-3 measurements. Atmos. Chem. Phys., 9, 897908, https://doi.org/10.5194/acp-9-897-2009.

Klaes, K. D., and Coauthors, 2007: An introduction to the EUMETSAT polar system. Bull. Amer. Meteor. Soc., 88, 1085-1096, https://doi.org/10.1175/BAMS-88-7-1085.

Kopp, T. J., and Coauthors, 2014: The VIIRS Cloud Mask: Progress in the first year of S-NPP toward a common cloud detection scheme. J. Geophys. Res. Atmos., 119, 2441-2456, https://doi.org/10.1002/2013JD020458.

Kursinski, E., and Coauthors, 1996: Initial results of radio occultation observations of Earth's atmosphere using the global positioning system. Science, 271, 1107-1100, https://doi.org/ 10.1126/science.271.5252.1107.

Li, X., and X. Zou, 2017: Bias characterization of CrIS radiances at 399 selected channels with respect to NWP model simulations. Atmos. Res., 196, 164-181, https://doi.org/10.1016/ j.atmosres.2017.06.007.

Liang, D., and F. Weng, 2014: Evaluation of the impact of a new quality control method on assimilation of CrIS data in HWRF-GSI. Geosci. Remote Sens. Symp., Quebec City, Quebec, Canada, IEEE, 3778-3781, https://doi.org/10.1109/ IGARSS.2014.6947306.

Lin, L., X. Zou, R. Anthes, and Y.-H. Kuo, 2010: COSMIC GPS radio occultation temperature profiles in clouds. Mon. Wea. Rev., 138, 1104-1118, https://doi.org/10.1175/2009MWR2986.1.

,-- , and F. Weng, 2017: Combining CrIS double $\mathrm{CO}_{2}$ bands for detecting clouds located in different layers of the atmosphere. J. Geophys. Res. Atmos., 122, 1811-1827, https:// doi.org/10.1002/2016JD025505.

Lin, Y., and K. E. Mitchell, 2005: The NCEP Stage II/IV hourly precipitation analyses: Development and applications. 19th Conf. on Hydrology, San Diego, CA, Amer. Meteor. Soc., 1.2, https://ams.confex.com/ams/Annual2005/techprogram/ paper_83847.htm.

McNally, A. P., and P. D. Watts, 2003: A cloud detection algorithm for high-spectral-resolution infrared sounders. Quart. J. Roy. Meteor. Soc., 129, 3411-3423, https://doi.org/10.1256/qj.02.208.

Mlawer, E. J., S. J. Taubman, P. D. Brown, and M. J. Iacono, 1997: Radiative transfer for inhomogeneous atmospheres: RRTM, a validated correlated-k model for the longwave. J. Geophys. Res., 102, 16 663-16 682, https://doi.org/10.1029/97JD00237.

Monin, A. S., and A. M. Obukhov, 1954: Basic laws of turbulent mixing in the ground layer of the atmosphere. Tr. Geofiz. Inst., Akad. Nauk SSSR, 151, 163-187.

Noh, Y., W. G. Cheon, S.-Y. Hong, and S. Raasch, 2003: Improvement of the K-profile model for the planetary boundary layer based on large eddy simulation data. Bound.-Layer Meteor., 107, 401-427, https://doi.org/10.1023/A:1022146015946.

Palmer, P. I., J. Barnett, J. Eyre, and S. Healy, 2000: A nonlinear optimal estimation inverse method for radio occultation measurements of temperature, humidity, and surface pressure. J. Geophys. Res., 105, 17513-17 526, https://doi.org/ 10.1029/2000JD900151.
Prunet, P., J. N. Thépaut, and V. Cassé, 1998: The information content of clear sky IASI radiances and their potential for numerical weather prediction. Quart. J. Roy. Meteor. Soc., 124, 211-241, https://doi.org/10.1002/qj.49712454510.

Rocken, C., and Coauthors, 1997: Analysis and validation of GPS/ MET data in the neutral atmosphere. J. Geophys. Res., 102, 29 849-29 866, https://doi.org/10.1029/97JD02400.

Schrøder, T., S. Leroy, M. Stendel, and E. Kaas, 2003: Validating the microwave sounding unit stratospheric record using GPS occultation. Geophys. Res. Lett., 30, 1734, https://doi.org/ 10.1029/2003GL017588.

Smith, A., N. Atkinson, W. Bell, and A. Doherty, 2015: An initial assessment of observations from the Suomi-NPP satellite: Data from the Cross-track Infrared Sounder (CrIS). Atmos. Sci. Lett., 16, 260-266, https://doi.org/10.1002/asl2.551.

Strow, L. L., and Coauthors, 2013: Spectral calibration and validation of the Cross-track Infrared Sounder (CrIS) on the Suomi NPP satellite. J. Geophys. Res. Atmos., 118, 12 486-12 496, https://doi.org/10.1002/2013JD020480.

Tobin, D., and Coauthors, 2013: Suomi-NPP CrIS radiometric calibration uncertainty. J. Geophys. Res. Atmos., 118, 10589 10600 , https://doi.org/10.1002/jgrd.50809.

Wang, L., and Coauthors, 2013: Geolocation assessment for CrIS sensor data records. J. Geophys. Res. Atmos., 118, 12690 12 704, https://doi.org/10.1002/2013JD020376.

Weng, F., 2007: Advances in radiative transfer modeling in support of satellite data assimilation. J. Atmos. Sci., 64, 3799-3807, https://doi.org/10.1175/2007JAS2112.1.

Wickert, J., G. Beyerle, R. König, S. Heise, L. Grunwaldt, G. Michalak, C. Reigber, and T. Schmidt, 2005: GPS radio occultation with CHAMP and GRACE: A first look at a new and promising satellite configuration for global atmospheric sounding. Ann. Geophys., 23, 653-658, https://doi.org/10.5194/ angeo-23-653-2005.

Wu, W. S., R. J. Purser, and D. F. Parrish, 2002: Three-dimensional variational analysis with spatially inhomogeneous covariances. Mon. Wea. Rev., 130, 2905-2916, https://doi.org/10.1175/15200493(2002)130<2905:TDVAWS > 2.0.CO;2.

Yang, S., and X. Zou, 2012: Assessments of cloud liquid water contributions to GPS radio occultation refractivity using measurements from COSMIC and CloudSat. J. Geophys. Res., 117, D06219, https://doi.org/10.1029/2011JD016452.

Zhu, Y., J. Derber, A. Collard, D. Dee, R. Treadon, G. Gayno, and J. A. Jung, 2014a: Enhanced radiance bias correction in the National Centers for Environmental Prediction's Gridpoint Statistical Interpolation data assimilation system. Quart. J. Roy. Meteor. Soc., 140, 1479-1492, https://doi.org/10.1002/qj.2233. , and Coauthors, 2014b: Variational bias correction in the NCEP's data assimilation system. 19th Int. TOVS Conf., Jeju Island, South Korea, TOVS 13 pp., http://cimss.ssec.wisc.edu/ itwg/itsc/itsc19/program/papers/10_02_zhu.pdf.

Zou, X., L. Lin, and F. Weng, 2014: Absolute calibration of ATMS upper level temperature sounding channels using GPS RO observations. IEEE Trans. Geosci. Remote Sens., 52, 13971406, https://doi.org/10.1109/TGRS.2013.2250981. 